\title{
Comparação dos métodos simplificado e de simulação propostos no novo regulamento brasileiro de etiquetagem de edificações públicas
}

\author{
Comparison of the simplified and simulation methods \\ proposed in the new Brazilian regulations for the labeling \\ of public buildings
}

\author{
Breno Pontes Pimentel \\ Arthur Santos Silva \\ Andréa Teresa Riccio Barbosa \\ Marcelo de Miranda Reis
}

\section{Resumo}

${ }^{1}$ Breno Pontes Pimente ${ }^{1}$ Universidade Federal do Mato Grosso do Sul Campo Grande - MS - Brasil

${ }^{2}$ Andréa Teresa Riccio Barbosa 2Universidade Federal do Mato Grosso do Sul Campo Grande - MS - Brasil

${ }^{3}$ Arthur Santos Silva ${ }^{3}$ Universidade Federal do Mato Grosso do Sul

Campo Grande - MS - Brasil

${ }^{4}$ Marcelo de Miranda Reis ${ }^{4}$ Instituto Militar de Engenharia Rio de Janeiro - RJ - Brasil

Recebido em 25/09/20 Aceito em 12/12/20

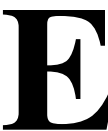

m 2018, houve Consulta Pública da Instrução Normativa INMETRO para Classe de Eficiência Energética de Edificações Comerciais, de Serviços e Públicas (INI-C), para substituição do Regulamento Técnico da Qualidade para o Nível de Eficiência Energética de Edificações (RTQ-C). O objetivo deste artigo foi comparar os resultados obtidos pela aplicação dos métodos simplificado e de simulação da INI-C, em um Pavilhão do Exército Brasileiro. Foram avaliados dois programas de simulação (DesignBuilder e EnergyPlus), três tipos de modelagem de cobertura (conforme projeto, modelada como material equivalente de mesmas propriedades térmicas de projeto, e adiabática), dois tipos de arquivos climáticos ("SWERA" e "INMET 2016"), e dois tipos de objetos para modelagem do sistema de condicionamento de ar da edificação ("PTAC" e "IdealLoads"), perfazendo 52 cenários, que foram comparados entre si. Em todos os cenários, obteve-se ENCE Geral de Projeto classe "A", porém com diferenças de consumos energéticos. Concluiu-se que os resultados obtidos por ambos os métodos da INI-C são compatíveis, ainda mais quando se utiliza arquivo climático "SWERA".

Palavras-chave: Eficiência energética. INI-C. RTQ-C. EnergyPlus. DesignBuilder.

\section{Abstract}

In 2018, a public consultation was held on the INMETRO Normative Instruction for Energy Efficiency Class for Commercial, Service and Public Buildings (INI-C), aimed at updating and replacing the Technical Quality Regulation for the Energy Efficiency Level of Buildings (RTQ-C). The aim of this paper is to compare the results obtained by applying the INI-C's simplified and simulation methods in a Brazilian Army pavilion. The authors evaluated two simulation softwares (DesignBuilder and EnergyPlus), three types of roof modelling (according to the design, modelled as equivalent material with the same thermal properties as the design, and adiabatic), two types of weather files ("SWERA" and "INMET 2016"), and two types of objects for modelling the building's air conditioning system ("PTAC" and "IdealLoads"). On the whole, 52 scenarios were compared to each other. In all scenarios, the ENCE obtained was class " $A$ ", but with differences in energy consumption. It was concluded that the results obtained by both INI-C methods are compatible, especially when using the weather file "SWERA".

Keywords: Energy efficiency. INI-C.RTQ-C. EnergyPlus. DesignBuilder. 


\section{Introdução}

Nos últimos anos, em todo o mundo, tem crescido o consumo energético, principalmente no setor de edificações. Em 2019, as edificações representaram 36\% do consumo energético total no mundo, com tendências crescentes. Apenas entre 2010 e 2018, o uso final de energia nos edifícios aumentou em quase 9\% (INTERNATIONAL..., 2018a, 2018b, 2019a, 2019b).

No contexto de aumento de demanda energética e de crescimento econômico e populacional, a eficiência energética tem importância crucial na construção de um futuro sustentável, com benefícios não somente ambientais, mas também econômicos (MOTHERWAY, 2019).

Segundo Fossati et al. (2016), uma maneira de reduzir o consumo energético dos edifícios é o estabelecimento de políticas de regulação, de avaliação e de classificação do desempenho energético desses. Corroboram com essa afirmação Evans e Shui (2009), que afirmam que códigos energéticos de edifícios podem garantir a redução do consumo de energia em até $50 \%$, quando comparados a edifícios que não aplicam técnicas de eficiência energética, com economia de recursos financeiros.

Nesse sentido, desde 2014 há no Brasil uma Instrução Normativa do Ministério do Planejamento, Orçamento e Gestão-MPOG (hoje Ministério da Economia) dispondo algumas regras para compras governamentais. A Instrução estabelece que tanto os projetos quanto as edificações públicas federais, novas ou que recebam retrofit, devem obter a Etiqueta Nacional de Conservação de Energia (ENCE) nível "A" (MINISTÉRIO..., 2014). Os métodos para avaliação energética desse tipo de edificação são previstos no Regulamento Técnico da Qualidade para o nível de eficiência energética de edificações comerciais, de serviços e públicas, RTQ-C (INSTITUTO..., 2012).

Há, entretanto, várias limitações e imprecisões encontradas na aplicação do RTQ-C (BAVARESCO et al., 2017; MELO et al., 2012, 2013; YAMAKAWA; WESTPHAL, 2011), o que motivou sua atualização, dando origem à Instrução Normativa INMETRO para Classe de Eficiência Energética de Edificações Comerciais, de Serviços e Públicas (INI-C). Esse novo regulamento define a atualização e a substituição do RTQ-C e passou por processo de consulta pública (INSTITUTO..., 2018).

O Exército Brasileiro, como órgão público, deve obter ENCE Geral nível "A" nos seus projetos e nas suas edificações construídas. Entre 2019 e 2021 está sendo construído em Campo Grande, MS, um pavilhão militar que foi projetado antes da publicação da Consulta Pública da INI-C para atender aos requisitos para obtenção de ENCE nível "A", quando avaliado pelo método prescritivo do RTQ-C (RACHID, 2018). Com a mudança, é recomendável uma nova avaliação conforme o novo regulamento.

O objetivo deste artigo é comparar a aplicação do método simplificado e do método de simulação da INI-C (INSTITUTO..., 2018), quando aplicados na avaliação da eficiência energética de um pavilhão do Exército Brasileiro. Foram incorporados diferentes cenários para a comparação, de maneira a investigar diferentes possibilidades de modelagem e de configuração de algumas variáveis no processo de avaliação (e o seu impacto no desempenho estudado). Essa análise exploratória visa subsidiar, juntamente com outros fatores não abordados neste artigo, a escolha pela aplicação de um ou outro método na avaliação energética de outras edificações militares desse mesmo tipo.

\section{Referencial teórico}

Desde 2014, o Centro Brasileiro de Eficiência Energética em Edificações (CB3E) e o PROCEL Edifica têm atuado na melhoria do método de avaliação do nível de eficiência energética de edificações comerciais, de serviços e públicas (CENTRO..., 2019a).

O método prescritivo do RTQ-C utiliza um indicador de consumo, que permite a classificação de níveis de "A" até "E", mas que não está associado a um consumo energético real ou potencial da edificação analisada. Esse fato, que impede a quantificação da economia gerada pela implementação de medidas energeticamente eficientes, foi um dos motivos para atualização do RTQ-C, que passará a ser denominada INI-C (CENTRO..., 2019a).

Outros estudos também apontaram limitações do RTQ-C: Yamakawa e Westphal (2011) variaram parâmetros de fator solar dos vidros e percentual de abertura de fachada com aplicação do método prescritivo e de simulação, obtendo diferentes níveis de eficiência entre os métodos. Melo et al. (2012) avaliaram a precisão do método prescritivo por meio do BESTEST (Building Energy Simulation Test), obtendo resultados fora do limite estabelecido e, para uma mesma edificação, foram observadas diferenças de desempenho quando avaliada pelo método prescritivo e pelo método de simulação, concluindo que o 
RTQ-C necessitava de atualizações para corrigir as falhas na avaliação do desempenho energético das edificações.

Com a finalidade de mitigar os problemas citados, Melo et al. (2013) buscaram utilizar redes neurais artificiais (RNA) e método Hipercubo Latino para propor um novo método simplificado para avaliação de edifícios comerciais. Nesse sentido, Versage (2015) desenvolveu um metamodelo baseado em RNA para estimar a carga térmica anual de refrigeração e para avaliar o desempenho energético de edificações condicionadas artificialmente. Bavaresco et al. (2017) verificaram a precisão desse metamodelo por meio de uma análise de sensibilidade, concluindo que esse apresenta predição aceitável na determinação de carga térmica das edificações, podendo ser aplicado em regulamentos brasileiros, tais como o RTQ-C. De fato, o metamodelo foi implementado enquanto método simplificado na INI-C (CENTRO..., 2019b).

Na INI-C são analisados os seguintes sistemas da edificação para fins de obtenção de ENCE: envoltória, condicionamento de ar, iluminação, equipamentos instalados, aquecimento de água e, apenas para fins informativos, percentual de economia devido ao uso racional de água (INSTITUTO..., 2018). Nessa instrução, cada sistema ou mesmo o edifício completo é classificado com base no percentual de economia de energia primária da edificação real em relação à edificação de referência, a qual representa classe "D" de eficiência energética (INSTITUTO..., 2018). A energia primária é aquela disponível na natureza antes de sofrer qualquer transformação, contida nos combustíveis ainda brutos. Tal conceito foi introduzido, pois quando há diferentes fontes de energia (e.g., elétrica e térmica) sendo utilizadas para um uso final, é recomendável que a classificação de eficiência energética de um sistema leve em consideração todas as fontes de energia utilizadas, o que pode ser feito por fatores de conversão de energia (CENTRO..., 2017).

No novo regulamento há dois métodos para avaliação dos consumos: o método simplificado (Anexo B da INI-C) e o método de simulação (Anexo C da INI-C). Um método prescritivo (com base em um checklist) ainda está sendo desenvolvido (CENTRO..., 2017).

Para aplicação do método simplificado da INI-C, os desenvolvedores criaram um endereço eletrônico para uso de um metamodelo que utiliza RNA para o cálculo da carga térmica anual de refrigeração, para as condições reais e de referência da edificação em análise (CENTRO..., 2019b). Tendo-se o valor da carga térmica, pode-se calcular o consumo de energia do sistema de condicionamento de ar, conforme equações expressas na INI-C. Também há outras equações para cálculo do consumo energético dos sistemas de iluminação, de aquecimento de água e dos equipamentos instalados.

No método de simulação da INI-C, há vantagens em relação ao método de simulação do RTQ-C. No método antigo, o analista deveria modelar quatro edifícios de referência (níveis " $A$ " até " $D$ " de eficiência energética) e mais o edifício real. Na INI-C, há necessidade de modelagem apenas do edifício real e de um edifício de referência (Classe "D”). Além disso, o Anexo A da INI-C traz tabelas com diversos parâmetros construtivos a serem adotados nesses dois modelos, enquanto no RTQ-C esses não eram expressos diretamente (deveriam ser calculados indiretamente por equações do método prescritivo).

Mesmo atualmente em consulta pública, há algumas publicações que utilizaram a INI-C: Vieira et al. (2019) avaliaram uma edificação educacional localizada em Belo Horizonte, MG, pelo método prescritivo do RTQC e pelo simplificado da INI-C, obtendo ENCE Parcial de Envoltória Nível " $C$ " (devido ao não atendimento de pré-requisitos, reduzindo do nível "A" para o "C") pelo RTQ-C e "A" pela INI-C; Fontana, Fonseca e Pereira (2019) avaliaram o impacto do entorno edificado na disponibilidade de luz natural e no consumo energético do sistema de iluminação de uma edificação comercial localizada em São Paulo, SP. A classificação energética dessa edificação nos diferentes cenários avaliados foi realizada pela INI-C, uma vez que essa dispõe de um método para contabilização de economia de energia devido aproveitamento de luz natural.

\section{Método}

Foram aplicados os dois métodos disponíveis nesse regulamento, o método simplificado e o de simulação, avaliando o impacto do uso de diferentes parâmetros nos resultados obtidos, tais como formas de modelagem da cobertura da edificação (adiabática, conforme projeto, e modelada como material equivalente de mesmas propriedades térmicas), softwares de simulação (EnergyPlus e DesignBuilder), arquivos climáticos ("SWERA" e "INMET 2016") e objetos de modelagem do sistema de condicionamento de ar ("PTAC" e "IdealLoads"). No total, foram comparados os resultados (consumo energético e ENCE) obtidos por 52 cenários, que diferem entre si por essas características. 


\section{Caracterização do objeto de pesquisa}

O pavilhão militar avaliado é do tipo Companhia de Comando e Apoio (Pav CCAp), que é uma tipologia comum a praticamente todos os quartéis do Exército em todo o território nacional, e está sendo construído na cidade de Campo Grande, MS. A edificação apresenta formato "H" (Figura 1), sendo composto por um bloco do lado leste e um bloco do lado oeste, ligados por uma circulação aberta nas laterais e com cobertura do mesmo material dos blocos. Podem-se observar também os elementos de sombreamento utilizados no projeto (varandas voltadas para todas as fachadas, e existência de cobogós na fachada oeste de ambos os blocos que formam o pavilhão. Esses cobogós são elementos de sombreamento com disposição tal que reduza a insolação na fachada oeste).

A área total construída do bloco do lado leste é de 487,70 m , formado por depósitos, vestiários, banheiros e circulações. A maioria dos ambientes desse lado é de permanência transitória, não condicionados artificialmente. A área total construída do bloco do lado oeste é de 467,80 m, formado por escritórios, sala de aula e circulações. Desse lado, a maioria dos ambientes é de permanência prolongada, condicionados artificialmente. O tipo de uso "escritórios", com atividades complementares a essa.

A cobertura dos ambientes fechados do pavilhão é formada por laje pré-moldada de $12 \mathrm{~cm}$ (concreto com espessura de $4 \mathrm{~cm}$, EPS com espessura de $7 \mathrm{~cm}$, e argamassa com espessura de $1 \mathrm{~cm}$ ), uma laje técnica de $1,60 \mathrm{~m}$ de altura, e telhas termoacústicas TB-30, da camada mais interna para a mais externa. Os fechamentos externos são todos em alvenaria de bloco cerâmico $(9 \mathrm{~cm}$ x $19 \mathrm{~cm}$ x $19 \mathrm{~cm})$, com argamassa interna e externa de $2,5 \mathrm{~cm}$. Foi considerado absortância solar $(\alpha)$ de 0,20 para as paredes internas e externas (pintura na cor branca), conforme Tabela 1.3 do Manual para Aplicação do RTQ-C (INSTITUTO..., 2016b). As aberturas são compostas por vidro simples, não refletivo, com $6 \mathrm{~mm}$ de espessura e fator solar de 0,82 .

O sistema de iluminação é composto por luminárias com duas lâmpadas de LED de $20 \mathrm{~W}$ e 2.600 lúmens cada. O sistema de condicionamento de ar, dos ambientes condicionados artificialmente, é composto por aparelhos do tipo Split Hi-Wall, Marca MIDEA ou equivalente técnico, de 9.000, 12.000 e 18.000 BTU/h, etiquetados pelo INMETRO com ENCE nível "A" e coeficiente de performance (COP) de 3,24.

A edificação foi projetada para atender a Instrução Normativa $n^{0} 02$ (MINISTÉRIO..., 2014), quando avaliada pelo método prescritivo do RTQ-C (mas ainda sem obtenção da ENCE por um OIA - organismo de inspeção acreditado).

\section{Método simplificado da INI-C}

$\mathrm{Na}$ aplicação do método simplificado da INI-C, avalia-se o desempenho térmico da envoltória pela comparação das cargas térmicas totais anuais da edificação obtidas utilizando um metamodelo disponível na internet (CENTRO..., 2019b).

O primeiro passo para uso desse metamodelo é a definição da tipologia da edificação que está sendo analisada. O Anexo A da INI-C permite a classificação em diversas tipologias, e, para cada uma delas, é fornecida uma tabela com caraterísticas gerais construtivas e de ocupação, que devem ser adotadas para avaliação energética, nas condições reais e de referência.

\section{Figura 1 - Vista em perspectiva do pavilhão do Exército Brasileiro avaliado pela INI-C}

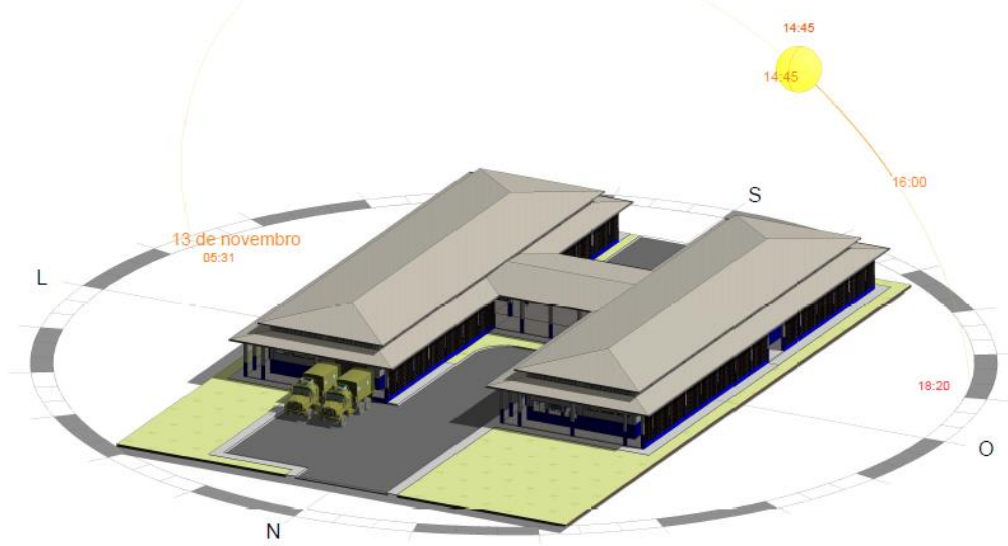

Fonte: Comissão de Obras do $3^{\circ}$ Grupamento de Engenharia (2017). 
O segundo passo é a divisão da edificação analisada em zonas térmicas, com o cálculo das áreas de cada zona. Esse procedimento se dá apenas para as áreas condicionadas artificialmente, sendo as demais não condicionadas e de permanência transitória, não avaliadas. As zonas térmicas devem ser divididas em zonas perimetrais e zonas internas, conforme a Figura 2. Os ambientes devem ainda ser divididos em zonas quando houver mudanças:

(a) no padrão de ocupação;

(b) no tipo e/ou especificação técnica do sistema de condicionamento de ar;

(c) na densidade de potência de iluminação e equipamentos (DPI e DPE);

(d) no contato com o piso (contato com o solo ou com o exterior);

(e) no contato com a cobertura (contato com outro cômodo ou com o exterior); $\mathrm{e}$

(f) no contato com a parede (contato com ambientes não condicionados artificialmente).

O terceiro passo é calcular os parâmetros de entrada do metamodelo, para cada zona térmica, para as condições reais e de referência, devendo-se seguir as diretrizes das tabelas do Anexo A da INI-C, para cada tipologia. Dentre os parâmetros, cita-se a área da zona térmica $(\mathrm{m})$, o tipo da zona térmica (perimetral ou interna), se a cobertura é voltada para o exterior, se existe isolamento térmico do piso, a orientação solar e todos os demais parâmetros listados na Figura 3 e na Tabela 1.

Em seguida, para a condição real e de referência, calcula-se o consumo anual de energia do sistema de condicionamento de ar (CCA), por meio dos valores de carga térmica anual (CgT), obtidos como dado de saída do metamodelo, dividindo-a pelo COP dos sistemas (COP real, para edificação real, e COP de referência obtido nas tabelas do Anexo A da INI-C dependendo da tipologia). Esse consumo pode ser de energia elétrica ou térmica, dependendo da alimentação do sistema de condicionamento de ar adotado.

Para obtenção do consumo anual do sistema de iluminação e dos equipamentos instalados em uma edificação, o método é semelhante: o valor da potência total instalada (de iluminação ou de equipamentos) é multiplicado pelo número de horas de utilização da edificação no dia e pelo número de dias de utilização no ano.

O número de horas e de dias de utilização é fixado em tabelas do Anexo A da INI-C, a depender da tipologia. Para edificações de escritório, por exemplo, conforme a Tabela 1 são 10 horas de ocupação por dia, durante 260 dias por ano.

O valor da potência total instalada de iluminação é obtido pela multiplicação da densidade de potência de iluminação (DPI) pela área iluminada, tanto para condição real (valor de DPI obtido em projeto), como para a condição de referência (valor de DPI obtido no Anexo A da INI-C, sendo, por exemplo, 14,1 W/m para edificações de escritório, conforme Tabela 1.

Figura 1 - Exemplo de divisão de ambientes em zonas térmicas
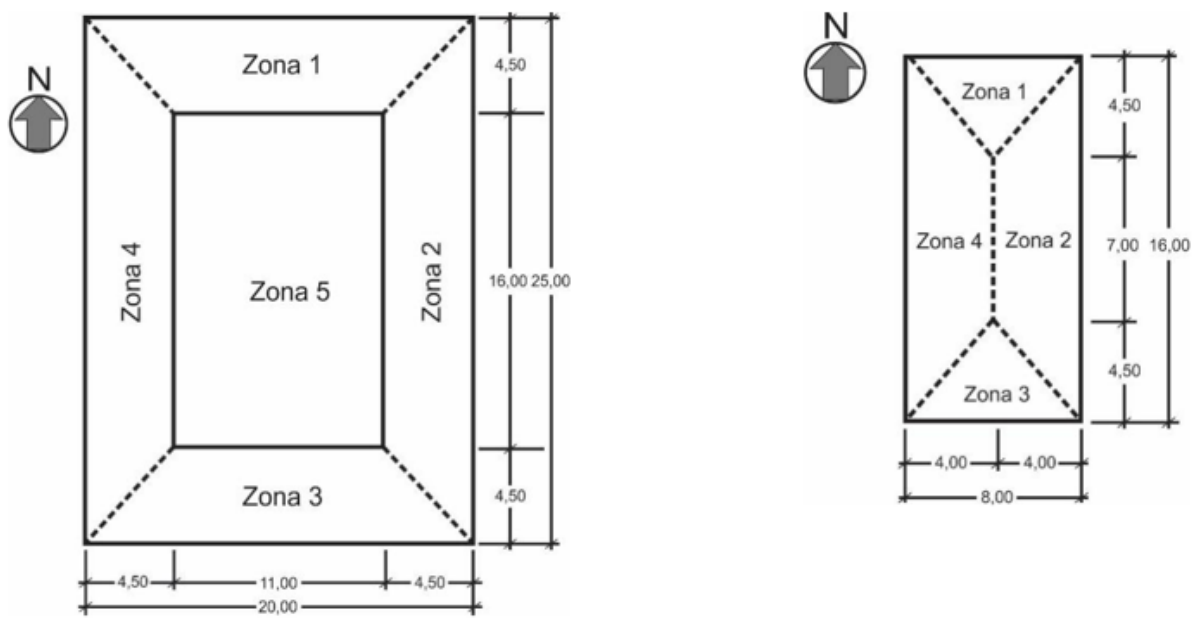

Fonte: INMETRO (INSTITUTO..., 2018).

Nota: o primeiro ambiente (esquerda) pôde ser dividido em zonas perimetrais e interna, por ter comprimento e largura superiores a $9 \mathrm{~m}$. 0 segundo ambiente apenas pôde ser dividido em zonas perimetrais. 
Figura 2 - Detalhes da tela do metamodelo para cálculo da carga térmica

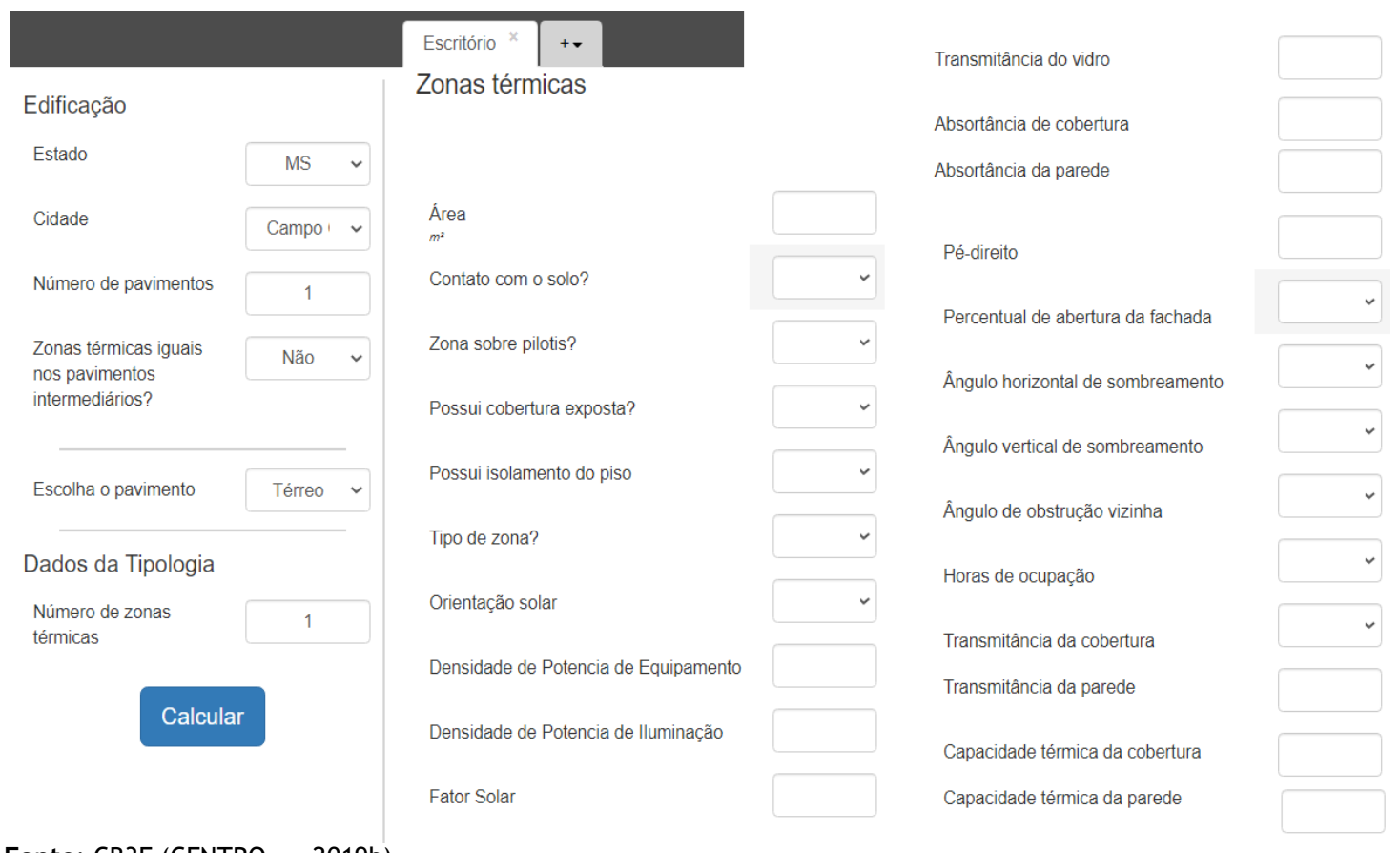

Fonte: CB3E (CENTRO..., 2019b).

Tabela 1 - Valores para avaliação energética de edificações de escritórios pela INI-C

\begin{tabular}{|c|c|c|}
\hline Classe & Variáveis & Referência \\
\hline Geometria & $\begin{array}{l}\text { Forma } \\
\text { Orientação solar }\left(^{\circ}\right) \\
\text { Pé-direito }(\mathrm{m}) \\
\text { AHS - Ângulo horizontal de sombreamento }\left(^{\circ}\right) \\
\text { AVS - Ângulo vertical de sombreamento }\left(^{\circ}\right) \\
\text { AOV - Ângulo de obstrução vertical }\left(^{\circ}\right)\end{array}$ & $\begin{array}{l}\text { Condição real } \\
\text { Condição real } \\
\text { Condição real } \\
0 \\
0 \\
\text { Condição real } \\
\text { (opcional) }\end{array}$ \\
\hline Aberturas & $\begin{array}{l}\text { PAF - Percentual de abertura da fachada (\%) } \\
\text { PAZ - Percentual de abertura zenital }(\%)\end{array}$ & $\begin{array}{l}50,00 \\
0,00 \\
\end{array}$ \\
\hline $\begin{array}{l}\text { Componentes } \\
\text { construtivos }\end{array}$ & $\begin{array}{l}\mathrm{U}_{\text {par- }} \text { transmitância térmica }(\mathrm{W} / \mathrm{m} \mathrm{K}) \text { paredes externas } \\
\alpha_{\text {par }}-\text { absortância térmica (adimensional) paredes externas } \\
\mathrm{CT}_{\text {par }}-\text { Capacidade térmica }(\mathrm{kJ} / \mathrm{m} \mathrm{K}) \text { paredes externas } \\
\mathrm{U}_{\mathrm{cob}} \text { - transmitância térmica }(\mathrm{W} / \mathrm{m} \mathrm{K}) \text { cobertura } \\
\alpha_{\mathrm{cob}}-\text { absortância térmica (adimensional) cobertura } \\
\mathrm{CT}_{\mathrm{cob}}-\text { Capacidade térmica }(\mathrm{kJ} / \mathrm{m} \mathrm{K}) \text { cobertura } \\
\mathrm{FS} \text { - Fator solar (adimensional) vidros } \\
\mathrm{U}_{\mathrm{vid}} \text { - transmitância térmica }(\mathrm{W} / \mathrm{m} \mathrm{K}) \text { vidros }\end{array}$ & $\begin{array}{l}2,39 \\
0,50 \\
150,00 \\
2,06 \\
0,80 \\
233,00 \\
0,82 \\
5,70\end{array}$ \\
\hline $\begin{array}{l}\text { Iluminação e } \\
\text { ganhos }\end{array}$ & $\begin{array}{l}\text { DPI - Densidade de potência de iluminação }(\mathrm{W} / \mathrm{m}) \\
\text { Ocupação (m /pessoa) } \\
\text { DPE - Densidade de potência de equipamentos }(\mathrm{W} / \mathrm{m}) \\
\text { Horas de ocupação (horas) } \\
\text { Dias de ocupação }\left(\mathrm{N}_{\text {ano }}\right) \\
\text { Condição do piso } \\
\text { Condição da cobertura } \\
\text { Isolamento do piso }\end{array}$ & $\begin{array}{l}14,10 \\
10,00 \\
9,70 \\
10,00 \\
260,00 \\
\text { Condição real } \\
\text { Condição real } \\
\text { Sem isolamento }\end{array}$ \\
\hline $\begin{array}{l}\text { Condicionamento } \\
\text { de ar }\end{array}$ & $\begin{array}{l}\text { COP - Coeficiente de performance }(\mathrm{W} / \mathrm{W}) \\
\text { Temperatura setpoint }\left({ }^{\circ} \mathrm{C}\right) \\
\text { Aquecimento de água }\end{array}$ & $\begin{array}{l}2,60 \\
24,00 \\
\text { Não significativo }\end{array}$ \\
\hline
\end{tabular}

Fonte: INMETRO (INSTITUTO..., 2018). 
Para obter a potência instalada de equipamentos, multiplica-se a densidade de potência de equipamento (obtida nas tabelas do Anexo A da INI-C dependendo da tipologia) pela área de piso dos ambientes de permanência prolongada.

\section{Método de simulação da INI-C}

$\mathrm{Na}$ avaliação da edificação pelo método de simulação, por meio de softwares de simulação termoenergética de edificações (especificados a seguir), é obtido o consumo final de energia elétrica e térmica dos sistemas individuais (condicionamento de ar, iluminação e equipamentos instalados). Comparando-se o consumo primário (simulado) do edifício na condição real com o consumo na condição de referência, obtém-se a classificação energética da edificação.

Segundo a INI-C, podem ser utilizados diversos softwares de simulação termoenergética, desde que atendam algumas características previstas no Anexo C da INI-C. Assim, com o intuito de identificar um conjunto de ferramentas e metodologias mais adequadas à simulação termoenergética de edificações do tipo avaliado, foram analisadas duas combinações:

(a) modelagem, caracterização e simulação termoenergética no software DesignBuilder versão 6.1.0.006, que utiliza como algoritmo o EnergyPlus versão 8.9.0.001 (Figura 4); e

(b) modelagem no software SketchUp versão Pro 2017 e no software OpenStudio versão 2.8.0, e caracterização e simulação termoenergética no software EnergyPlus versão 9.1.0 (Figura 5).

Para a modelagem da edificação analisada, nas condições reais e de referência, características como transmitância térmica e absortância solar das paredes e coberturas, propriedades dos vidros, percentual de abertura na fachada (PAF), ângulos horizontais e verticais de sombreamento (AHS e AVS), COP do sistema de condicionamento de ar, e densidade de potência de iluminação (DPI), dentre outras, foram definidas conforme tabelas do Anexo A da INI-C para cada condição. A Tabela 1, por exemplo, expressa condições e valores que devem ser adotados na condição de referência, para a tipologia de escritórios.

Considerou-se a ocupação da edificação nos horários de $8 \mathrm{~h} 00 \mathrm{~min}$ as $18 \mathrm{~h} 00 \mathrm{~min}$, de segunda a sexta, nos quais funcionam todos os sistemas (iluminação, equipamentos e condicionamento de ar). Como simplificação, considerou-se $100 \%$ de carga de cada ganho térmico interno em todas as horas de uso, de acordo com Versage (2015). Os fins de semana foram considerados sem ocupação. Esse tipo de utilização está de acordo com o padronizado no Anexo A da INI-C para edificações de escritório.

Figura 4 - Modelagem da edificação na condição real, no software DesignBuilder

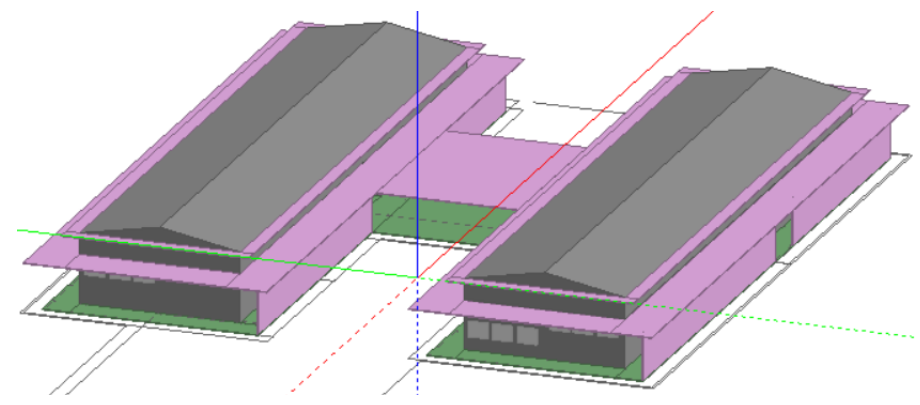

Figura 3 - Modelagem da edificação na condição real, no software ScketchUp/OpenStudio

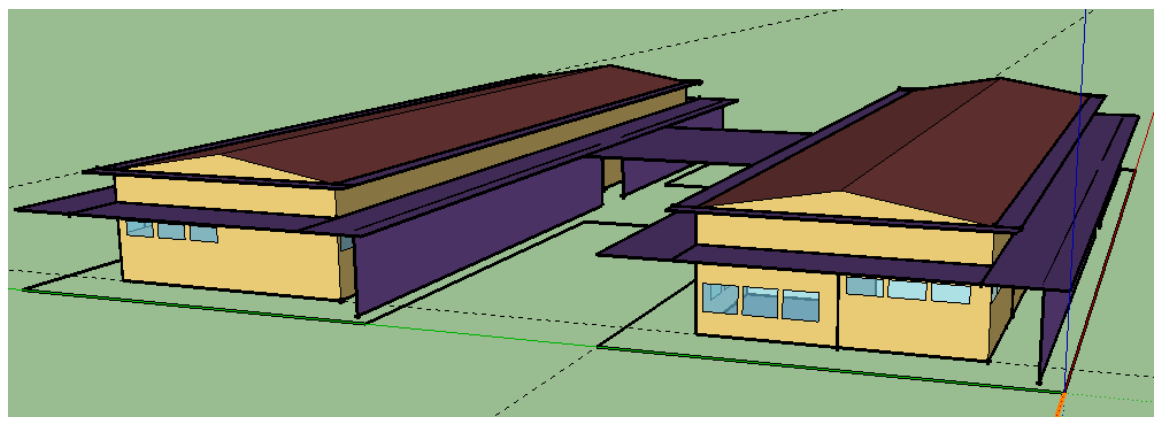


De acordo com Versage (2015), considerou-se o total de ganho de calor por pessoa de $120 \mathrm{~W}$, condizente com uma atividade média de escritório desempenhada pelos ocupantes. Fixou-se a fração radiante dos ganhos de calor sensível pelas pessoas em $30 \%$, sendo o restante de $70 \%$ assumido como carga térmica por convecção. Fixou-se a fração radiante das cargas internas do sistema de iluminação e dos equipamentos em $72 \%$ e a fração convectiva em $10 \%$, sendo o restante de $18 \%$ a fração visível das lâmpadas ou a fração de trabalho dos equipamentos. Na modelagem, para minimizar divergências entre os resultados obtidos com os softwares utilizados em decorrência de possível diferença na área útil dos ambientes, optou-se por utilizar valores de ocupação, de equipamentos e de iluminação em números absolutos, não em densidade.

Para modelagem do sistema de condicionamento de ar, foram utilizados objetos Packaged Terminal Air Conditioner (PTAC) e "IdealLoads". Ambos são componentes disponibilizados pelo EnergyPlus (e pelo DesignBuilder) que permitem simulação energética do sistema de condicionamento de ar. O "PTAC" considera uma modelagem conjunta (para simulação coordenada) de um dispositivo misturador de ar externo, de dispositivos de resfriamento de expansão direita e de um ventilador, permitindo a obtenção como dado de saída do consumo energético anual do sistema (com COP real variável em função da operação do sistema) e da carga térmica anual, por exemplo. Já o "IdealLoads" considera a modelagem de um sistema ideal de condicionamento de ar que seria capaz de atender todos os parâmetros definidos (e.g. setpoint e umidade do ar) sem consumir energia, sendo utilizado frequentemente para obtenção de carga térmica em situações nas quais se quer prever o desempenho energético de uma edificação sem se modelar um sistema de condicionamento de ar específico (DEPARTMENT..., 2019).

Pelo uso do "IdealLoads", conforme prevê a INI-C, pode-se obter indiretamente uma previsão de consumo energético, pela divisão da carga térmica obtida pelo valor médio do COP (fixo). A modelagem por cada um desses objetos exige alguns parâmetros de entrada específicos, dentre os quais os principais foram expressos na Tabela 2.

Tabela 2 - Dados de entrada do objeto PTAC e do IdealLoads para modelagem de sistema de condicionamento de ar

\begin{tabular}{|c|c|c|}
\hline Parâmetro & IdealLoads & PTAC \\
\hline \multirow{8}{*}{ Mesma condição } & \multicolumn{2}{|c|}{ Modelagem de um sistema para cada zona térmica } \\
\hline & \multicolumn{2}{|c|}{ Setpoint $\left(24^{\circ} \mathrm{C}\right)$} \\
\hline & \multicolumn{2}{|c|}{$\begin{array}{l}\text { Disponibilidade do sistema de aquecimento } \\
\text { (sempre desligado) }\end{array}$} \\
\hline & \multicolumn{2}{|c|}{$\begin{array}{l}\text { Disponibilidade do sistema de resfriamento } \\
\text { (8h00min-18h00min de segunda a sexta) }\end{array}$} \\
\hline & \multicolumn{2}{|c|}{$\begin{array}{l}\text { Temperatura mínima de insuflamento de ar para } \\
\text { resfriamento }\left(13^{\circ} \mathrm{C}\right)\end{array}$} \\
\hline & \multicolumn{2}{|c|}{$\begin{array}{l}\text { Método de cálculo de vazão externa de ar (vazão } \\
\text { por área) }\end{array}$} \\
\hline & \multicolumn{2}{|c|}{ Vazão externa de ar por área $(0,0004$ m /s-m $)$} \\
\hline & \multicolumn{2}{|c|}{ Controle de insuflamento de ar constante } \\
\hline $\begin{array}{l}\text { Umidade mínima de insuflamento de ar para } \\
\text { resfriamento }\end{array}$ & $\begin{array}{l}0,0077 \mathrm{~kg} \\
\text { água } / \mathrm{kg} \text { ar Seco }\end{array}$ & Não se aplica \\
\hline Fator de dimensionamento de resfriamento & Sem limite & 1,15 \\
\hline Auto dimensionamento & $\begin{array}{l}\text { Fluxo de ar } \\
(\mathrm{m} / \mathrm{s})\end{array}$ & $\begin{array}{l}\text { Capacidade }(\mathrm{W}) \text { e fluxo de ar } \\
(\mathrm{m} / \mathrm{s})\end{array}$ \\
\hline Posicionamento dos ventiladores para insuflamento & Não se aplica & Drawthrough \\
\hline $\begin{array}{l}\text { Eficiência total dos ventiladores para insuflamento } \\
\text { de ar }\end{array}$ & Não se aplica & $65 \%$ \\
\hline Pressão de ar dos ventiladores para insuflamento & Não se aplica & $250 \mathrm{~Pa}$ \\
\hline $\begin{array}{l}\text { Eficiência do motor dos ventiladores para } \\
\text { insuflamento }\end{array}$ & Não se aplica & $90 \%$ \\
\hline COP médio do sistema bruto de refrigeração & Não se aplica & 3,24 \\
\hline Tipo do sistema bruto de refrigeração & Não se aplica & Elétrico \\
\hline $\begin{array}{l}\text { Diferença de temperatura de insuflamento de ar } \\
\text { para resfriamento }\end{array}$ & Não se aplica & $11^{\circ} \mathrm{C}$ \\
\hline
\end{tabular}

186 Pimentel, B. P.; Silva, A. S.; Barbosa, A. T. R.; Reis, M. de M. 


\section{Obtenção do consumo anual total e da ENCE Geral de Projeto}

Após avaliação desses sistemas individualmente, obteve-se o consumo total anual da edificação pela Equação 1. Nesse artigo, uma vez que só há método simplificado para cálculo do consumo anual de energia elétrica do sistema de aquecimento de água, optou-se por não o avaliar, já que se pretende comparar a aplicação do método simplificado e de simulação da INI-C. A edificação militar também não apresenta geração local de energia, zerando essa parcela na Equação 1.

$C T E_{E}=C I L+C C A_{E}+C A A_{E}+C E Q-G E_{E}$

Eq. 1

Onde:

$C T E_{E}$ é o consumo anual total de energia elétrica da edificação (kWh/ano);

$C I L$ é o consumo anual total de energia elétrica do sistema de iluminação (kWh/ano);

$C C A_{E}$ é o consumo anual total de energia elétrica do sistema de condicionamento de ar (kWh/ano);

$C A A_{E}$ é o consumo anual total de energia elétrica do sistema de aquecimento de água (kWh/ano);

$C E Q$ é o consumo anual total de energia elétrica dos equipamentos instalados ( $\mathrm{kWh} / \mathrm{ano})$; e

$G E_{E}$ é geração total anual de energia elétrica por fonte local renovável (kWh/ano).

Após o cálculo do consumo energético anual total, obteve-se o consumo total anual de energia primária da edificação, conforme a Equação 2.

$C E P_{R E A L ~ O U R E F}=f_{C E} \times C T E_{E}+f_{C T} \times C T E_{T}$

Eq. 2

Onde:

$C E P_{R E A L ~ O U ~ R E F}$ é o consumo total de energia primária da edificação, que pode ser em sua condição real $\left(\mathrm{CEP}_{\mathrm{REAL}}-\mathrm{kWh} / \mathrm{ano}\right)$ ou de referência $\left(\mathrm{CEP}_{\mathrm{REF}}-\mathrm{kWh} / \mathrm{ano}\right)$;

$f_{C E}$ é o fator de conversão de energia elétrica para energia primária, igual a 1,6;

$C T E_{E}$ é o consumo total anual de energia elétrica da edificação avaliada (kWh/ano), obtido pela Equação 1;

$f_{C T}$ é o fator de conversão de energia térmica para energia primária, igual a 1,1, tanto para gás natural, como para gás liquefeito de petróleo; e

$C T E_{T}$ é o consumo total anual de energia térmica da edificação avaliada (kWh/ano), quando existente. Para essa edificação, não há fontes térmicas.

Calculou-se o percentual de economia de energia da edificação real em relação à edificação de referência, pela Equação 3.

$P R C E P_{R E A L-D}=1-\frac{C E P}{C E P_{R E F}} * 100$

Eq. 3

Onde:

$P R C E P_{R E A L-D}$ é o percentual de redução do consumo de energia primária entre a condição real e de referência;

$C E P$ é o consumo anual de energia primária da edificação na condição real ( $\mathrm{kWh} / \mathrm{ano})$; e

$C E P_{R E F}$ é o consumo anual de energia primária da edificação na condição de referência (kWh/ano).

Para essa edificação, o lado leste apresenta fator de forma de 0,74 , e o lado oeste de 0,77 . Uma vez que o fator de forma dessa edificação de escritório é maior que 0,50, para a cidade de Campo Grande, MS - Grupo Climático 10 pela classificação de Roriz (2014) - pela Tabela 5 da INI-C (INSTITUTO..., 2018), obtém-se que o coeficiente de redução mínimo do consumo de energia primária da classe " $D$ " para a classe " $A$ " é de $38 \%$. Se a economia é maior que essa, classifica-se a edificação com ENCE Geral classe "A". Caso contrário, deve-se preencher uma tabela com intervalos de eficiência para obtenção de classes "B", "C", "D" ou "E". 


\section{Clima e arquivos climáticos do local de pesquisa}

O clima de Campo Grande, MS, onde edificação militar analisada está sendo construída, é tropical com inverno seco e verão chuvoso de acordo com a classificação de Köppen-Geiger (CLIMATE-DATA.ORG, 2020).

No treinamento do metamodelo do método simplificado da INI-C, Versage (2015) utilizou arquivo climático do tipo Test Reference Year (TRY) para a cidade de Florianópolis, SC. O metamodelo permite, como dado de entrada, a utilização de outras cidades brasileiras. Entretanto, não há evidências de qual arquivo climático foi utilizado para realizar o treinamento do metamodelo, para cada uma delas. A cidade de Campo Grande, MS, por exemplo, nem dispõe de arquivos TRY.

Segundo a INI-C, podem ser utilizados quaisquer arquivos climáticos, desde que sejam aprovados pelo laboratório de referência e que atendam algumas características, como fornecer dados horários de temperatura, umidade, radiação solar, direção e velocidade do vento (INSTITUTO..., 2018). Ainda, sugerese que seja utilizado arquivo climático INMET 2016 publicado em LABEEE/UFSC (LABORATÓRIO..., 2019).

Cabe ressaltar que, para Campo Grande, MS, foram observadas variações nos valores de temperatura de bulbo seco, umidade relativa e irradiação solar, entre os arquivos climáticos SWERA (Solar and Wind Energy Resource Assessment) e INMET 2016 (Instituto Nacional de Meteorologia), conforme Figuras 6 e 7.

As médias horárias anuais de temperatura de bulbo seco, de umidade relativa, de radiação solar global horizontal e de radiação solar direta normal são, respectivamente, 2,53\%; 4,06\%; 6,34\%; e 138,54\% maiores no arquivo climático SWERA que no INMET 2016. Portanto, na escolha dos cenários a serem avaliados neste artigo, optou-se pela consideração de ambos os arquivos climáticos.

\section{Cenários avaliados}

Para avaliação da edificação, foram utilizados o metamodelo baseado em RNA (CENTRO..., 2019b) do método simplificado, e os software EnergyPlus e DesignBuilder.

Conforme já mencionado, na aplicação do método de simulação, foram utilizadas a modelagem do sistema de condicionamento de ar com o objeto "IdealLoads" e com o objeto "PTAC" e os arquivos climáticos SWERA e INMET 2016.

Figura 6 - Médias diárias de temperatura de bulbo seco, radiação solar direta e global, e umidade relativa de Campo Grande, MS ("SWERA") - o eixo x representa os meses e as horas do dia

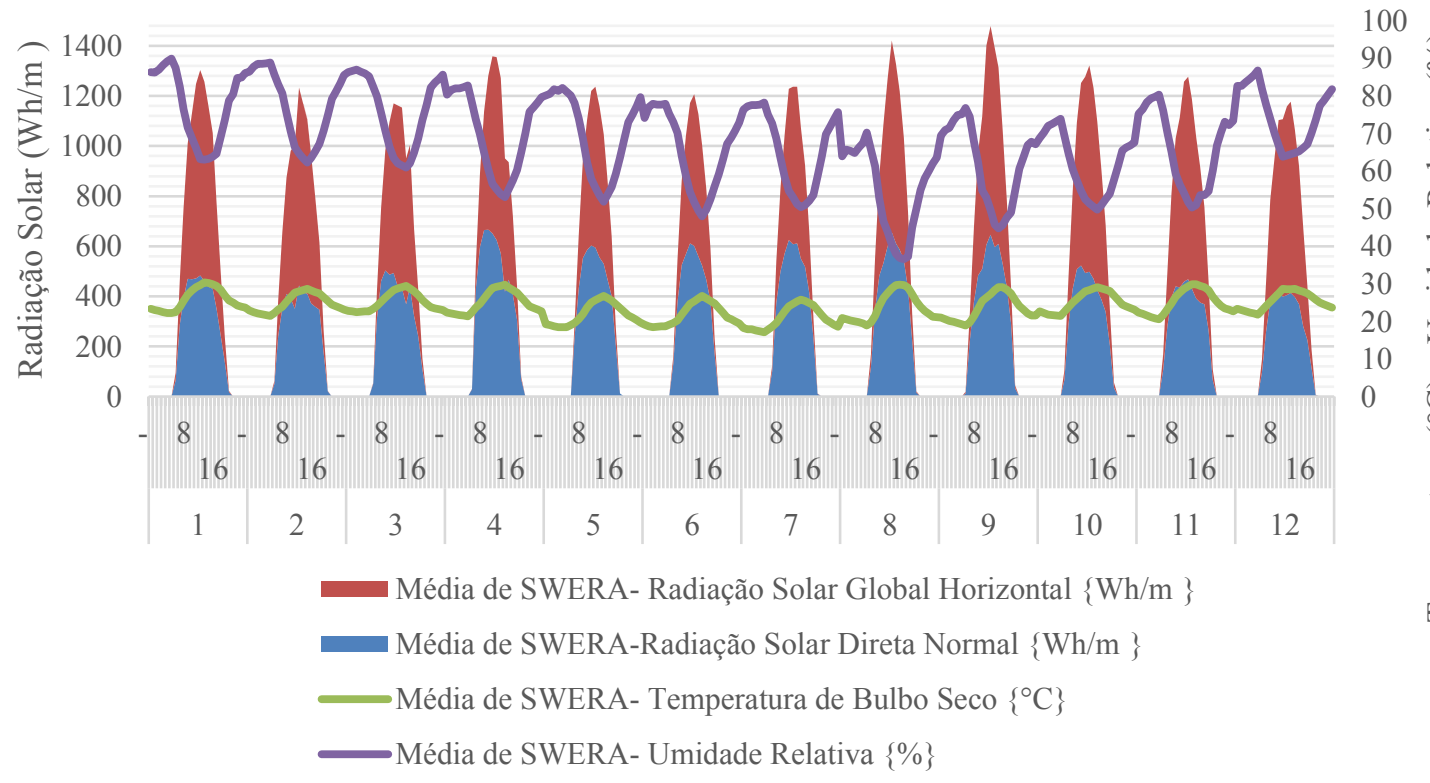


Figura 4 - Médias diárias de temperatura de bulbo seco, radiação solar direta e global, e umidade relativa de Campo Grande, MS ("INMET 2016") - o eixo x representa os meses e as horas do dia

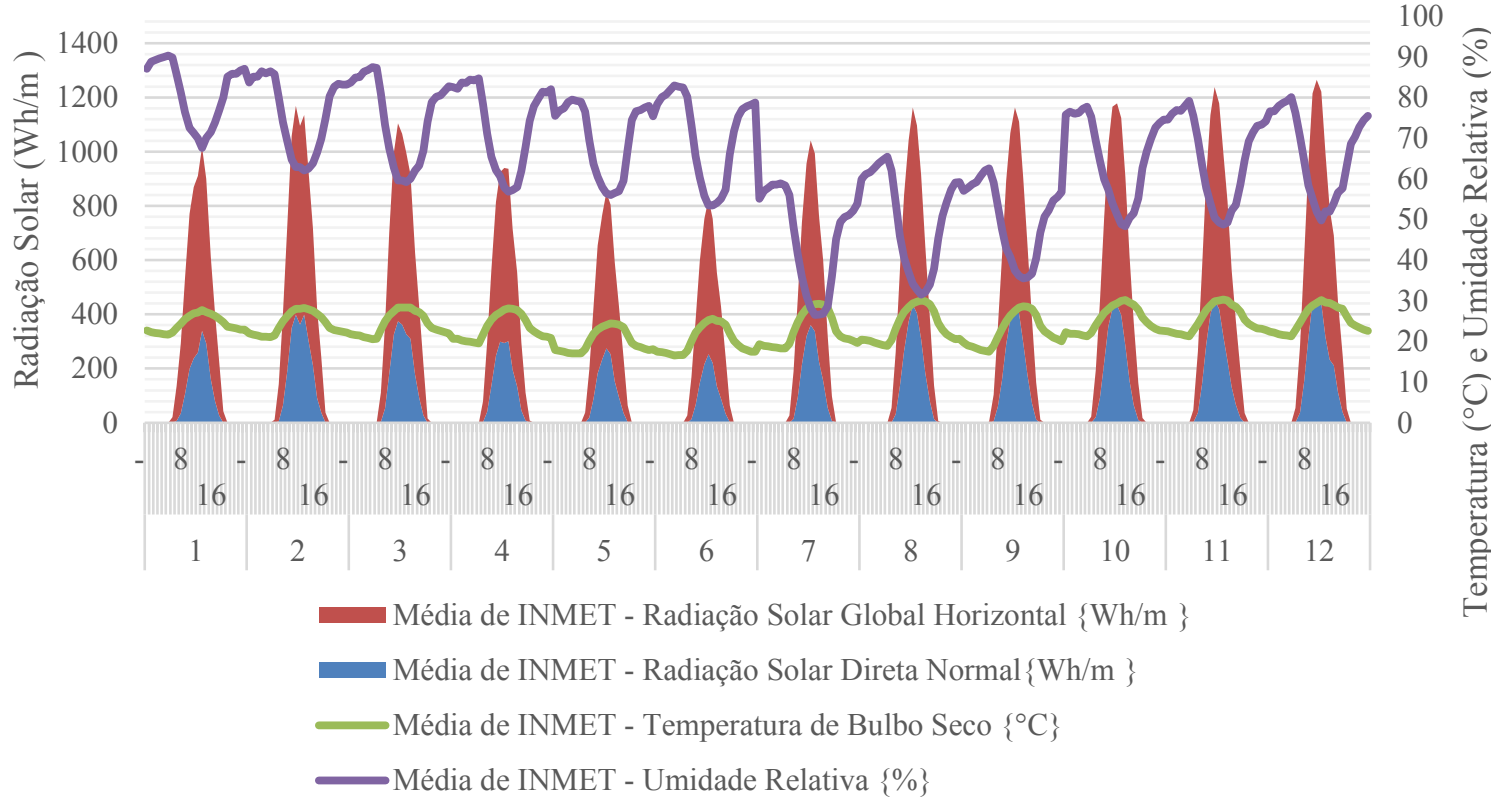

Quanto à modelagem geométrica da edificação, a laje técnica que compõe a cobertura é uma zona térmica que não pode ser avaliada pelo metamodelo disponível, mas apenas pelas simulações. Assim, decidiu-se modelar a cobertura de três formas:

(a) tal como no projeto (laje técnica atuando como Zona Térmica - ZT);

(b) eliminando a laje técnica e considerando o teto de todas as zonas térmicas como um elemento formado por camadas uniformes, sobrepostas da seguinte forma (Comp Equiv): laje de espessura $12 \mathrm{~cm}$ com EPS (argamassa com espessura $1 \mathrm{~cm}+$ camada de EPS espessura $7 \mathrm{~cm}+$ concreto com espessura $4 \mathrm{~cm}$ ) + camada de ar (espessura de 1,6 m) + telha termoacústica TB-30 (lâmina de alumínio de $1 \mathrm{~cm}$ de espessura + camada de poliuretano de $4 \mathrm{~cm}$ de espessura + lâmina de alumínio de $1 \mathrm{~cm}$ de espessura), da camada mais interna para a mais externa, nessa ordem; e

(c) considerando o teto de todas as zonas térmicas como um elemento adiabático formado por uma laje de espessura $12 \mathrm{~cm}$ com EPS (argamassa com espessura $1 \mathrm{~cm}+$ camada de EPS espessura $7 \mathrm{~cm}+$ concreto com espessura $4 \mathrm{~cm}$, da camada mais interna para a mais externa, nessa ordem). Esta maneira visa emular um pavimento intermediário que não tenha a cobertura em contato com o exterior, a qual seria uma das interpretações possíveis para a consideração do pavimento nas análises energéticas.

Para o caso "a" e "b", no método simplificado, a cobertura é caracterizada como um material equivalente da cobertura n. 19, do Anexo V da Portaria INMETRO n. 50/2013, com transmitância térmica de 0,53 W/m K e capacidade térmica de $176 \mathrm{~kJ} / \mathrm{m} \mathrm{K}$ (INSTITUTO..., 2016a). Para o caso "c", no método simplificado, a cobertura é caracterizada como sem contato com o exterior (adiabática) e, por isso, não é possível preencher dados de transmitância, capacidade térmica e absortância da cobertura no metamodelo (CENTRO..., 2019b). Em todos os casos, as paredes externas seguem o modelo n. 41, do Anexo V da Portaria INMETRO n. $50 / 2013$, com transmitância térmica de $2,39 \mathrm{~W} / \mathrm{m} \mathrm{K}$ e capacidade térmica de $151 \mathrm{~kJ} / \mathrm{m} \mathrm{K}$ (INSTITUTO..., 2016a).

No total, foram avaliados 52 cenários, conforme a Tabela 3, comparando o resultado de carga térmica de resfriamento, de consumo energético simulado e de ENCE obtida por cada um. Assim, pode ser verificada a diferença entre os resultados obtidos pela aplicação do método simplificado e pela aplicação do método de simulação da INI-C, nessa mesma edificação, determinando se os métodos são compatíveis. Ainda, pode-se apontar as configurações (objetos de modelagem de sistema de condicionamento de ar, arquivos climáticos e modelos de cobertura) que aproximam os resultados. 
Tabela 3 - Cenários avaliados, onde RNA refere-se ao método simplificado, E+ ao software EnergyPlus, e DB, ao software DesignBuilder

\begin{tabular}{|c|c|c|c|c|c|}
\hline ID & Modelo & Ferramenta & HVAC & Arquivo climático & Cobertura \\
\hline 1 & REAL & RNA & & & Comp Equiv \\
\hline 2 & REAL & RNA & & & Adiabática \\
\hline 3 & REAL & $\mathrm{E}+$ & IdealLoads & SWERA & ZT \\
\hline 4 & REAL & $\mathrm{E}+$ & IdealLoads & SWERA & Comp Equiv \\
\hline 5 & REAL & $\mathrm{E}+$ & IdealLoads & SWERA & Adiabática \\
\hline 6 & REAL & $\mathrm{E}+$ & IdealLoads & INMET & ZT \\
\hline 7 & REAL & E+ & IdealLoads & INMET & Comp Equiv \\
\hline 8 & REAL & $\mathrm{E}+$ & IdealLoads & INMET & Adiabática \\
\hline 9 & REAL & $\mathrm{E}+$ & PTAC & SWERA & ZT \\
\hline 10 & REAL & $\mathrm{E}+$ & PTAC & SWERA & Comp Equiv \\
\hline 11 & REAL & E+ & PTAC & SWERA & Adiabática \\
\hline 12 & REAL & E+ & PTAC & INMET & $\mathrm{ZT}$ \\
\hline 13 & REAL & E+ & PTAC & INMET & Comp Equiv \\
\hline 14 & REAL & $\mathrm{E}+$ & PTAC & INMET & Adiabática \\
\hline 15 & REAL & DB & IdealLoads & SWERA & ZT \\
\hline 16 & REAL & DB & IdealLoads & SWERA & Comp Equiv \\
\hline 17 & REAL & DB & IdealLoads & SWERA & Adiabática \\
\hline 18 & REAL & DB & IdealLoads & INMET & ZT \\
\hline 19 & REAL & $\mathrm{DB}$ & IdealLoads & INMET & Comp Equiv \\
\hline 20 & REAL & $\mathrm{DB}$ & IdealLoads & INMET & Adiabática \\
\hline 21 & REAL & DB & PTAC & SWERA & ZT \\
\hline 22 & REAL & DB & PTAC & SWERA & Comp Equiv \\
\hline 23 & REAL & DB & PTAC & SWERA & Adiabática \\
\hline 24 & REAL & $\mathrm{DB}$ & PTAC & INMET & ZT \\
\hline 25 & REAL & DB & PTAC & INMET & Comp Equiv \\
\hline 26 & REAL & DB & PTAC & INMET & Adiabática \\
\hline 27 & REFERÊNCIA & RNA & & & Comp Equiv \\
\hline 28 & REFERÊNCIA & RNA & & & Adiabática \\
\hline 29 & REFERÊNCIA & $\mathrm{E}+$ & IdealLoads & SWERA & ZT \\
\hline 30 & REFERÊNCIA & E+ & IdealLoads & SWERA & Comp Equiv \\
\hline 31 & REFERÊNCIA & E+ & IdealLoads & SWERA & Adiabática \\
\hline 32 & REFERÊNCIA & $\mathrm{E}+$ & IdealLoads & INMET & ZT \\
\hline 33 & REFERÊNCIA & $\mathrm{E}+$ & IdealLoads & INMET & Comp Equiv \\
\hline 34 & REFERÊNCIA & $\mathrm{E}+$ & IdealLoads & INMET & Adiabática \\
\hline 35 & REFERÊNCIA & $\mathrm{E}+$ & PTAC & SWERA & ZT \\
\hline 36 & REFERÊNCIA & $\mathrm{E}+$ & PTAC & SWERA & Comp Equiv \\
\hline 37 & REFERÊNCIA & $\mathrm{E}+$ & PTAC & SWERA & Adiabática \\
\hline 38 & REFERÊNCIA & E+ & PTAC & INMET & ZT \\
\hline 39 & REFERÊNCIA & $\mathrm{E}+$ & PTAC & INMET & Comp Equiv \\
\hline 40 & REFERÊNCIA & $\mathrm{E}+$ & PTAC & INMET & Adiabática \\
\hline 41 & REFERÊNCIA & $\mathrm{DB}$ & IdealLoads & SWERA & ZT \\
\hline 42 & REFERÊNCIA & $\mathrm{DB}$ & IdealLoads & SWERA & Comp Equiv \\
\hline 43 & REFERÊNCIA & DB & IdealLoads & SWERA & Adiabática \\
\hline 44 & REFERÊNCIA & DB & IdealLoads & INMET & ZT \\
\hline 45 & REFERÊNCIA & DB & IdealLoads & INMET & Comp Equiv \\
\hline 46 & REFERÊNCIA & DB & IdealLoads & INMET & Adiabática \\
\hline 47 & REFERÊNCIA & $\mathrm{DB}$ & PTAC & SWERA & ZT \\
\hline 48 & REFERÊNCIA & DB & PTAC & SWERA & Comp Equiv \\
\hline 49 & REFERÊNCIA & DB & PTAC & SWERA & Adiabática \\
\hline 50 & REFERÊNCIA & DB & PTAC & INMET & ZT \\
\hline 51 & REFERÊNCIA & DB & PTAC & INMET & Comp Equiv \\
\hline 52 & REFERÊNCIA & DB & PTAC & INMET & Adiabática \\
\hline
\end{tabular}


Para melhor entendimento, os resultados obtidos para cada cenário foram apresentados em gráfico com o consumo energético para todos os 52 cenários, com cálculo do consumo médio para a condição real e para condição de referência (para permitir a comparação do consumo de cada cenário com os consumos médios).

Em seguida, foram separados, dentre esses 52 cenários, os resultados obtidos pela utilização do arquivo climático "INMET 2016" e "SWERA", respectivamente. Essa divisão por arquivo climático foi importante porque essa variável foi a mais influente nos resultados. Optou-se por apresentar gráficos de carga térmica anual e de consumo energético anual para cada cenário, com cada um dos arquivos climáticos. Tal separação permitiu a determinação da diferença média entre o método de simulação e o método simplificado da INI-C, tanto para o "INMET 2016" quanto para o "SWERA", para análise de compatibilidade dos métodos com utilização de cada arquivo climático.

Posteriormente, foi apresentada uma análise comparativa entre os cenários, destacando a ENCE Geral de Projeto, a carga térmica e o consumo energético obtidos em cada um. Para o consumo energético, foram determinadas (em uma tabela) as diferenças percentuais entre os consumos obtidos em cada cenário, a fim de quantificar a diferença entre os resultados obtidos pelo método simplificado e pelo método de simulação.

Por fim, foi apresentada uma seção de discussão dos resultados, com menção às possíveis fontes de diferença entre os cenários.

\section{Resultados e discussões}

\section{Consumo energético total para todos os cenários}

A Figura 8 ilustra os consumos energéticos obtidos para cada cenário da Tabela 3.

Pode-se observar na Figura que o consumo energético, em todos os cenários onde foi utilizado arquivo climático "INMET 2016", ficou em média 6,16\% abaixo dos valores médios, independentemente das outras características de modelagem. Por outro lado, em todos os cenários onde foi utilizado arquivo climático "SWERA", assim como na avaliação da edificação pelo método simplificado, o consumo energético ficou acima dos valores médios, respectivamente, em média 5,66\% e 3,00\%.

Analisando os grupos de cenários de simulação com mesmo software, mesmo objeto de modelagem de ar condicionado, mesmo arquivo climático, mas variando a modelagem de cobertura (trios 3-4-5, 6-7-8, 9-1011, e assim sucessivamente), observa-se que, quando a cobertura é modelada como um componente equivalente, os consumos energéticos são, em média, 1,61\% e 3,06\% maiores do que quando a cobertura é modelada como no projeto (com zona térmica) e do que quando a cobertura é considerada adiabática, respectivamente.

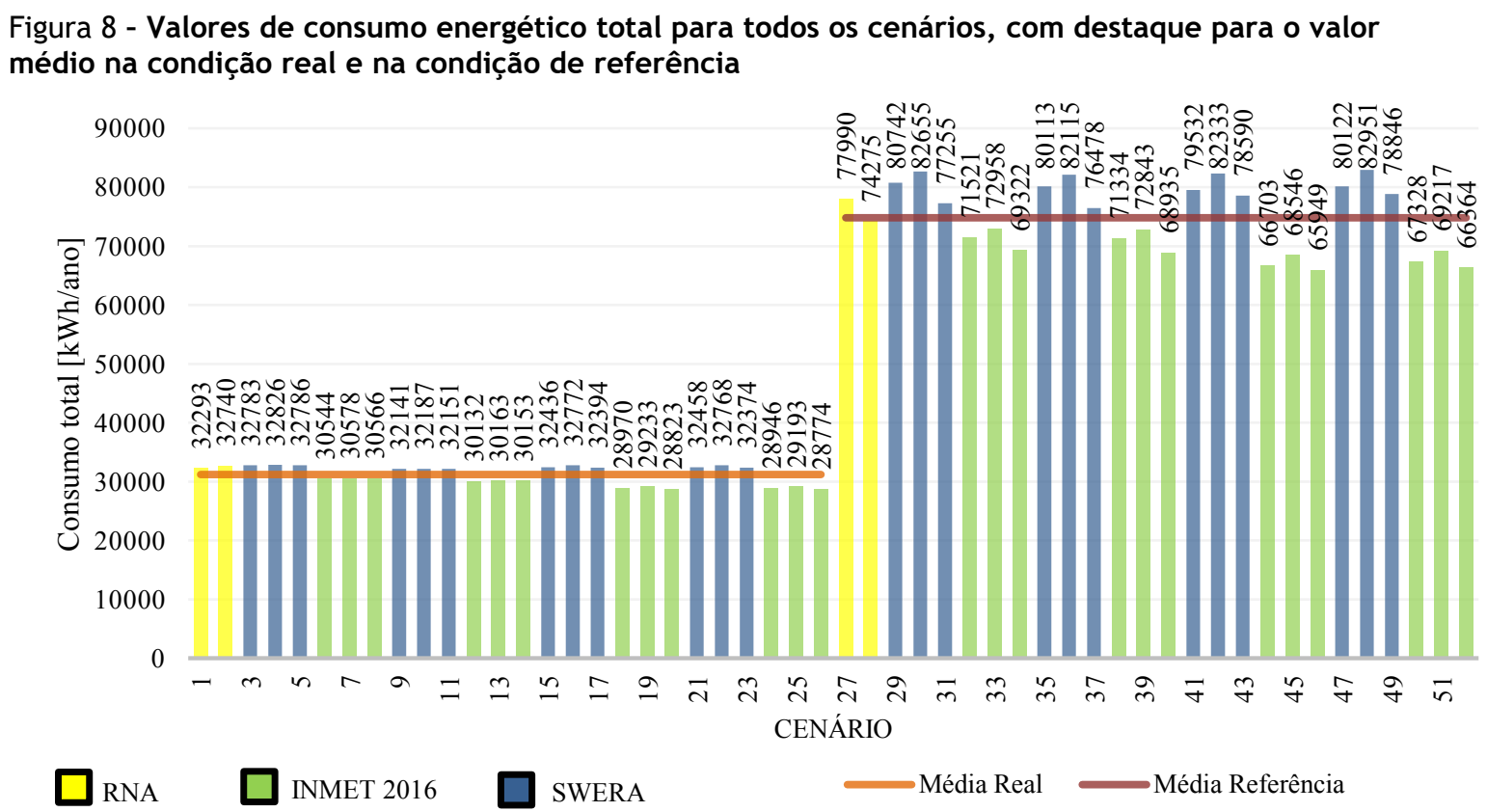




\section{Utilização de arquivo climático INMET 2016}

Quando utilizado o arquivo climático "INMET 2016" nas simulações, são obtidos valores de carga térmica de resfriamento menores (em média $-29,44 \%$, variando desde $-41,51 \%$ até $-17,53 \%$ ) que quando utilizado o método simplificado (RNA), nas condições real e de referência, conforme pode ser observado na Figura 9. O mesmo acontece com o consumo energético total (principalmente influenciado pelo reflexo da carga térmica no consumo do sistema de condicionamento de ar), que é, em média, 9,98\% menor (variando desde $-13,38 \%$ até $-4,17 \%$ ), como pode ser observado na Figura 10.

Esses parâmetros de consumo e carga térmica, por serem menores no método de simulação (com "INMET 2016”) que no método simplificado, reduzem a previsão de economia energética (em valores absolutos) e induzem nos tomadores de decisão o pensamento de que a edificação possa ser energeticamente eficiente. Por isso, pode-se dizer que são valores menos conservadores quando obtidos na avaliação energética de uma edificação.

Menores valores de consumo energético e de carga térmica obtidos por simulação são desejáveis apenas se o desempenho energético da edificação de fato seja superior ao previsto pelo método simplificado (e tenha sido mais bem refletido na simulação do que no metamodelo).

Uma vez que o metamodelo foi treinado com milhares de simulações, diferenças significativas nos consumos energéticos obtidos (pelo método simplificado e de simulação) para uma edificação de formas geométricas comuns como a avaliada são pouco prováveis. Além disso, como dito, não há evidências sobre qual arquivo climático foi de fato utilizado para o treinamento da rede em outras cidades, além de Florianópolis, SC. Esses fatos levam a crer que é provável que não foi "INMET 2016" para Campo Grande, MS, pois se fossem os consumos energéticos obtidos por simulação e pelo método simplificado seriam mais próximos.

\section{Figura 9 - Valores de carga térmica de resfriamento para todos os cenários (simulação com arquivo climático INMET 2016)}

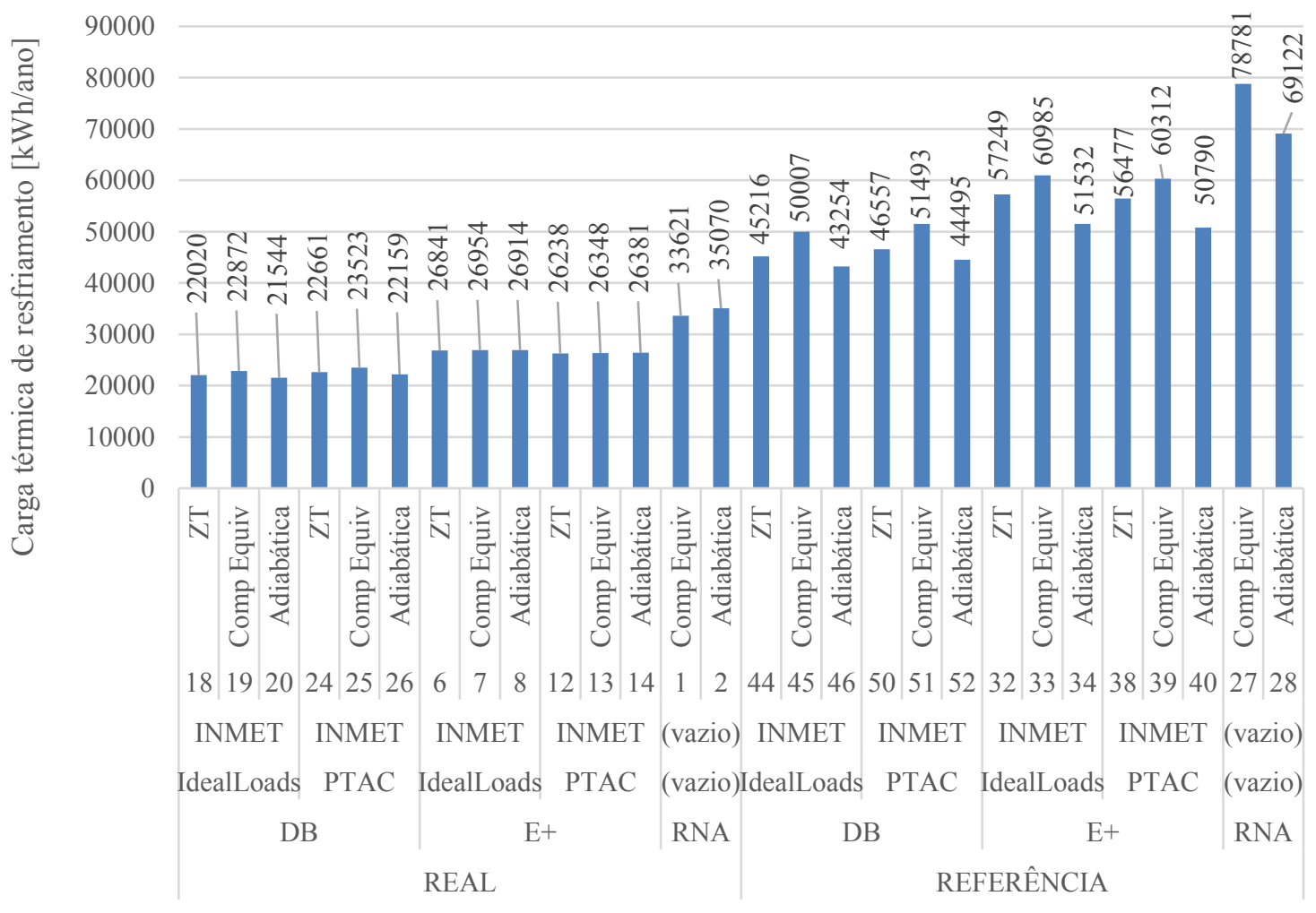

192 Pimentel, B. P.; Silva, A. S.; Barbosa, A. T. R.; Reis, M. de M. 
Figura 10 - Valores de consumo energético total para todos os cenários (simulação com arquivo climático INMET 2016), com destaque para os consumos individuais dos sistemas de iluminação, de condicionamento de ar e de equipamentos

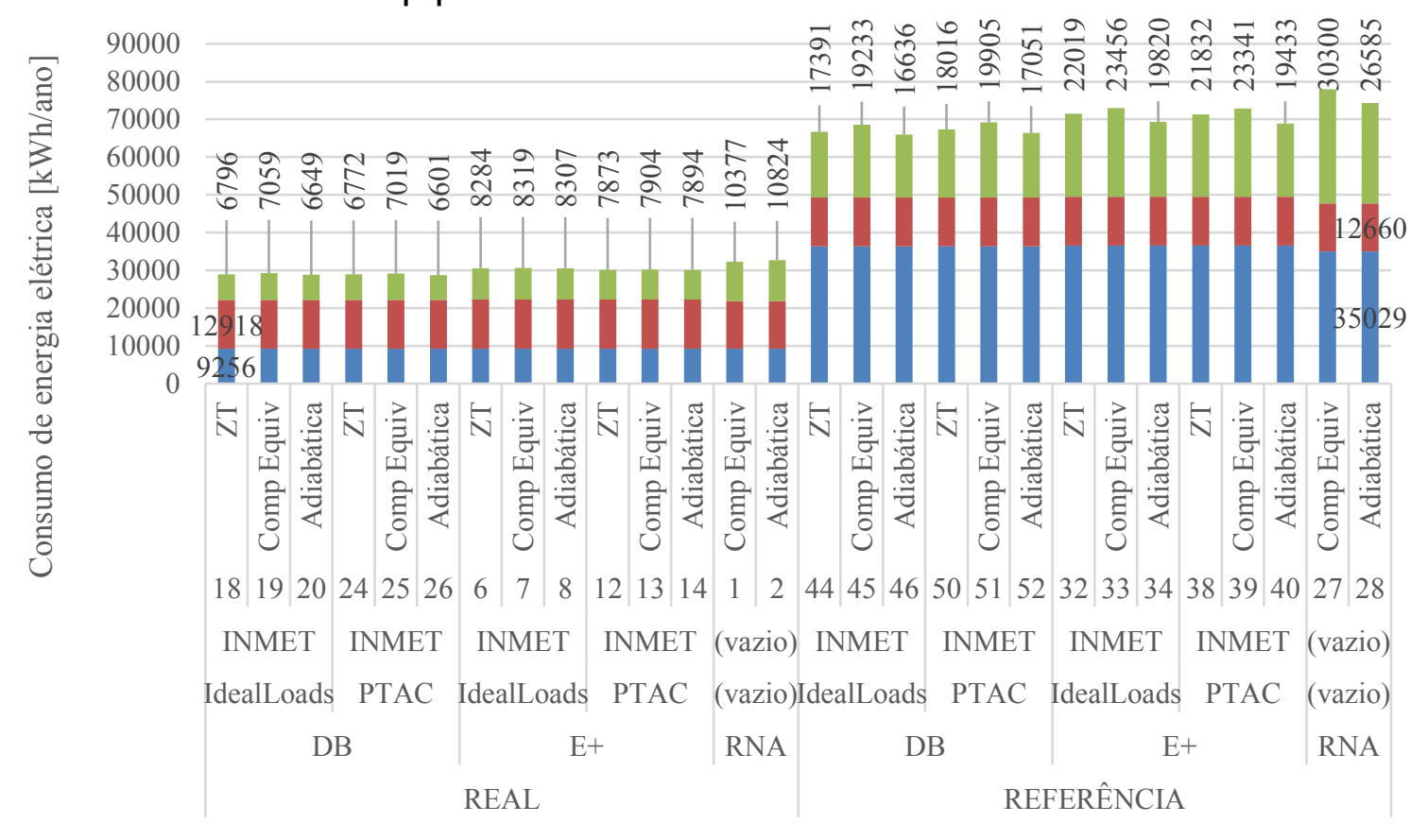

- Soma de Sistema de Iluminação

- Soma de Equipamentos Instalados

- Soma de Sistema de Condicionamento de Ar

\section{Utilização de arquivo climático SWERA}

Substituindo o arquivo climático "INMET 2016" pelo "SWERA", em todas as simulações, observa-se uma aproximação dos resultados de carga térmica e de consumo energético com aqueles obtidos pelo método simplificado. Foram obtidas cargas térmicas por simulação (com "SWERA"), em média, 3,33\% maiores (variando desde $-4,39 \%$ até $+18,70 \%$ ) que as obtidas pelo método simplificado. Já os consumos energéticos anuais, em média, $1,51 \%$ maiores (variando desde $-1,16 \%$ até $+8,96 \%$ ). De fato, ocorreu compatibilidade entre consumos obtidos pelo método simplificado e pelas simulações, uma vez que nenhuma diferença encontrada entre os métodos superou 8,96\%. As Figuras 11 e 12 ilustram os resultados obtidos.

\section{Análise comparativa entre os cenários}

\section{ENCE Geral de Projeto}

Em relação ao edifício real, em todos os casos analisados, o edifício de referência (equivalente à classe "D" de eficiência energética) apresentou maior consumo total anual de energia. Os percentuais de economia do edifício real em relação ao de referência, utilizados para obtenção da ENCE Geral de Projeto, estão representados na Tabela 4.

Como há apenas fontes de energia elétrica na edificação avaliada, o percentual de economia de energia primária converge com o percentual de economia de energia elétrica. Assim, como todas as economias ficaram acima de $38 \%$ (valor do coeficiente de redução do consumo de energia primária da classe "D" para a classe "A" para o grupo climático 10), por todos os métodos se obteve ENCE Geral de Projeto classe "A".

Portanto, apesar das diferenças entre os consumos energéticos obtidos, dentro de mesmo método (simplificado ou de simulação) não há prejuízo à ENCE, uma vez que essa é obtida comparando o consumo de energia primária do edifício real com o de referência, ambos calculados pelo mesmo método. Assim, do ponto de vista da obtenção de ENCE, não houve diferença entre os métodos utilizados. 
Figura 11 - Valores de carga térmica de resfriamento para todos os cenários (simulação com arquivo climático SWERA)

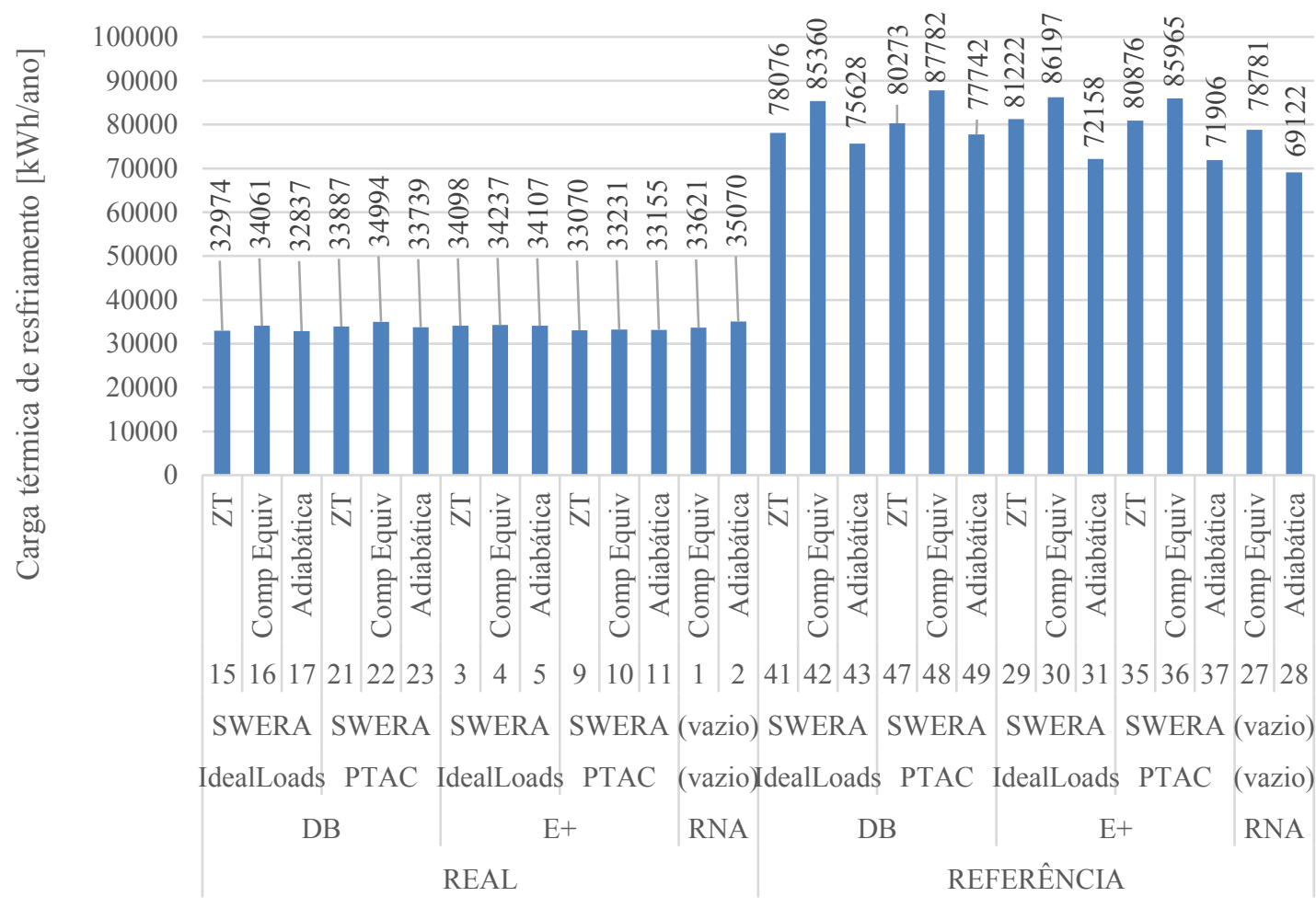

Figura 12 - Valores de consumo energético total para todos os cenários (simulação com arquivo climático SWERA), com destaque para os consumos individuais do sistema de iluminação, de condicionamento de ar e de equipamentos

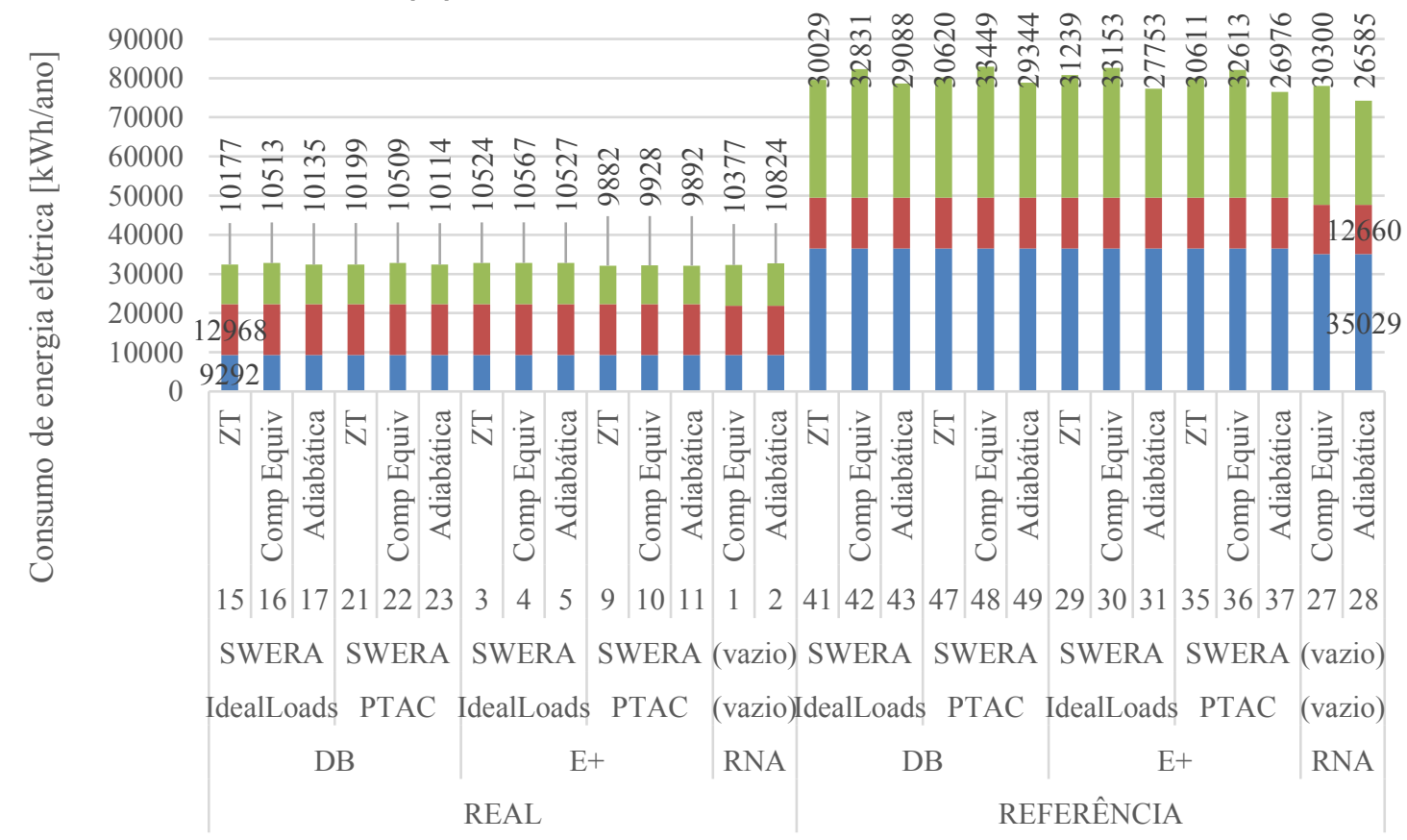

- Soma de Sistema de Iluminação

- Soma de Equipamentos Instalados

- Soma de Sistema de Condicionamento de Ar 
Tabela 4 - Percentual de economia (consumo energético anual do Edifício Real em relação ao do Edifício de Referência-Ref) para obtenção de ENCE Geral de Projeto

\begin{tabular}{|c|c|c|c|c|c|}
\hline \multicolumn{3}{|c|}{ Características da modelagem } & \multicolumn{3}{|c|}{ Economia (Ed Real - Ed Ref) } \\
\hline $\begin{array}{l}\text { Objeto } \\
\text { HVAC }\end{array}$ & Tipo de cobertura & $\begin{array}{c}\text { Arquivo } \\
\text { climático }\end{array}$ & $\begin{array}{c}\text { Simplifica } \\
\text { do }\end{array}$ & $\begin{array}{l}\text { Simulação - } \\
\text { EnergyPlus }\end{array}$ & $\begin{array}{c}\text { Simulação - } \\
\text { DesignBuilder }\end{array}$ \\
\hline IdealLoads & $\begin{array}{l}\text { Projeto (zona } \\
\text { térmica) }\end{array}$ & $\begin{array}{c}\text { SWERA } \\
\text { INMET } 2016\end{array}$ & $\begin{array}{l}58,59 \% \\
58,59 \%\end{array}$ & $\begin{array}{l}59,40 \% \\
57,29 \%\end{array}$ & $\begin{array}{l}59,22 \% \\
56,57 \%\end{array}$ \\
\hline $\begin{array}{l}\text { Objeto } \\
\text { HVAC }\end{array}$ & Tipo de cobertura & $\begin{array}{l}\text { Arquivo } \\
\text { climático }\end{array}$ & $\begin{array}{l}\text { Simplifi- } \\
\text { cado }\end{array}$ & $\begin{array}{l}\text { Simulação - } \\
\text { EnergyPlus }\end{array}$ & $\begin{array}{c}\text { Simulação - } \\
\text { DesignBuilder }\end{array}$ \\
\hline \multirow{2}{*}{ IdealLoads } & \multirow{2}{*}{$\begin{array}{l}\text { Componente } \\
\text { equivalente }\end{array}$} & SWERA & $58,59 \%$ & $60,29 \%$ & $60,20 \%$ \\
\hline & & INMET 2016 & $58,59 \%$ & $58,09 \%$ & $57,35 \%$ \\
\hline \multirow{2}{*}{ IdealLoads } & \multirow{2}{*}{ Adiabática } & SWERA & $55,92 \%$ & $57,56 \%$ & $58,78 \%$ \\
\hline & & INMET 2016 & $55,92 \%$ & $55,91 \%$ & $56,29 \%$ \\
\hline \multirow{2}{*}{ PTAC } & \multirow{2}{*}{$\begin{array}{l}\text { Projeto (zona } \\
\text { térmica) }\end{array}$} & SWERA & $58,59 \%$ & $59,88 \%$ & $59,49 \%$ \\
\hline & & INMET 2016 & $58,59 \%$ & $57,76 \%$ & $57,01 \%$ \\
\hline \multirow{2}{*}{ PTAC } & \multirow{2}{*}{$\begin{array}{l}\text { Componente } \\
\text { equivalente }\end{array}$} & SWERA & $58,59 \%$ & $60,80 \%$ & $60,50 \%$ \\
\hline & & INMET 2016 & $58,59 \%$ & $58,59 \%$ & $57,82 \%$ \\
\hline \multirow{2}{*}{ PTAC } & \multirow{2}{*}{ Adiabática } & SWERA & $55,92 \%$ & $57,96 \%$ & $58,94 \%$ \\
\hline & & INMET 2016 & $55,92 \%$ & $56,26 \%$ & $56,64 \%$ \\
\hline
\end{tabular}

\section{Carga térmica e consumo energético}

Como o metamodelo do método simplificado foi treinado por milhares de simulações, esperava-se que os resultados de carga térmica e de consumo energético, para cada cenário (mesmo sistema de condicionamento de ar, mesmo tipo de cobertura, mesma condição - real ou de referência, mesmo arquivo climático), fossem próximos quando utilizado o método simplificado e o método de simulação da INI-C. Porém, foram observadas as diferenças percentuais apresentadas na Tabela 5.

Para a modelagem da edificação real, com arquivo climático "SWERA", a maior diferença de consumo energético entre os métodos foi de 1,80\% em módulo (consumo energético obtido com EnergyPlus, com cobertura adiabática e objeto "PTAC"). No caso da edificação de referência, com "SWERA", a maior diferença foi de 6,36\% em módulo (consumo energético obtido com DesignBuilder, com componente equivalente de cobertura e objeto "PTAC"). Assim, quando utilizado o arquivo climático "SWERA", foi possível validar o consumo energético obtido pelo método simplificado por simulação, com boa correspondência (diferenças máximas de 6,36\%).

No caso da modelagem com o "SWERA" e com o sistema de condicionamento de ar modelado como "IdealLoads", observou-se que apenas alterando a modelagem da cobertura conforme projeto (como zona térmica) para um componente equivalente, há aumento (em média de 1,87\% para 3,67\%) das diferenças entre os resultados obtidos por simulação e o resultado obtido pelo método simplificado, uma vez que, quando modelado um componente equivalente de cobertura nos softwares de simulação, esses calculam automaticamente os valores de transmitância e de capacidade térmica, que por sua vez são diferentes dos utilizados no metamodelo do método simplificado.

Pela

Tabela 5, observa-se que as menores diferenças entre o método simplificado e o de simulação (e entre os softwares de simulação utilizados) ocorrem quando a cobertura é modelada como zona térmica, em todos os casos. O mesmo ocorre quando o sistema de condicionamento de ar é modelado pelo objeto "PTAC" ao invés do "IdealLoads".

Dessa forma, no geral, a modelagem que gera menor diferença entre os métodos (média de 1,37\%) é a com objeto "PTAC" de condicionamento de ar, com arquivo climático "SWERA", e com cobertura modelada como no projeto (com laje técnica funcionando como zona térmica). A maior diferença (média de 9,82\%) entre o método de simulação e o simplificado, na modelagem com objeto "PTAC", arquivo "INMET 2016", e cobertura de projeto. 
Tabela 5 - Comparação entre os resultados de consumo energético anual obtidos pelo método simplificado e de simulação da INI-C (com software EnergyPlus e DesignBuilder)

\begin{tabular}{|c|c|c|c|c|c|c|}
\hline \multicolumn{4}{|c|}{ Características da modelagem } & \multicolumn{3}{|c|}{ Diferenças percentuais } \\
\hline $\begin{array}{l}\text { Objeto } \\
\text { HVAC }\end{array}$ & $\begin{array}{c}\text { Tipo de } \\
\text { cobertura }\end{array}$ & $\begin{array}{c}\text { Condição do } \\
\text { modelo }\end{array}$ & $\begin{array}{l}\text { Arquivo } \\
\text { climático }\end{array}$ & $\begin{array}{l}\text { EnergyPlus - } \\
\text { simplificado }\end{array}$ & $\begin{array}{c}\text { DesignBuilder - } \\
\text { simplificado }\end{array}$ & $\begin{array}{c}\text { EnergyPlus - } \\
\text { DesignBuilder }\end{array}$ \\
\hline \multirow{4}{*}{ IdealLoads } & \multirow{4}{*}{$\begin{array}{l}\text { Projeto (zona } \\
\text { térmica) }\end{array}$} & \multirow{2}{*}{ Real } & SWERA & $1,52 \%$ & $0,44 \%$ & $1,07 \%$ \\
\hline & & & INMET 2016 & $-5,42 \%$ & $-10,29 \%$ & $5,43 \%$ \\
\hline & & \multirow{2}{*}{ Referência } & SWERA & $3,53 \%$ & $1,98 \%$ & $1,52 \%$ \\
\hline & & & INMET 2016 & $-8,29 \%$ & $-14,47 \%$ & $7,22 \%$ \\
\hline \multirow{4}{*}{ IdealLoads } & \multirow{4}{*}{$\begin{array}{l}\text { Componente } \\
\text { equivalente }\end{array}$} & \multirow{4}{*}{$\begin{array}{l}\text { Real } \\
\text { Referência }\end{array}$} & SWERA & $1,65 \%$ & $1,48 \%$ & $0,17 \%$ \\
\hline & & & INMET 2016 & $-5,31 \%$ & $-9,47 \%$ & $4,60 \%$ \\
\hline & & & SWERA & $5,98 \%$ & $5,57 \%$ & $0,39 \%$ \\
\hline & & & INMET 2016 & $-6,45 \%$ & $-12,11 \%$ & $6,44 \%$ \\
\hline \multirow{4}{*}{ IdealLoads } & \multirow{4}{*}{ Adiabática } & & SWERA & $0,14 \%$ & $-1,06 \%$ & $1,21 \%$ \\
\hline & & & INMET 2016 & $-6,64 \%$ & $-11,96 \%$ & $6,05 \%$ \\
\hline & & \multirow{2}{*}{ Referência } & SWERA & $4,01 \%$ & $5,81 \%$ & $-1,70 \%$ \\
\hline & & & INMET 2016 & $-6,67 \%$ & $-11,21 \%$ & $5,12 \%$ \\
\hline \multirow{4}{*}{ PTAC } & \multirow{4}{*}{$\begin{array}{l}\text { Projeto (zona } \\
\text { térmica) }\end{array}$} & \multirow{4}{*}{$\begin{array}{l}\text { Real } \\
\text { Referência }\end{array}$} & SWERA & $-0,47 \%$ & $0,51 \%$ & $-0,98 \%$ \\
\hline & & & INMET 2016 & $-6,69 \%$ & $-10,36 \%$ & $4,10 \%$ \\
\hline & & & SWERA & $2,72 \%$ & $2,73 \%$ & $-0,01 \%$ \\
\hline & & & INMET 2016 & $-8,53 \%$ & $-13,67 \%$ & $5,95 \%$ \\
\hline $\begin{array}{l}\text { Objeto } \\
\text { HVAC }\end{array}$ & $\begin{array}{l}\text { Tipo de } \\
\text { cobertura }\end{array}$ & $\begin{array}{l}\text { Condição do } \\
\text { modelo }\end{array}$ & $\begin{array}{l}\text { Arquivo } \\
\text { climático }\end{array}$ & $\begin{array}{l}\text { EnergyPlus - } \\
\text { simplificado }\end{array}$ & $\begin{array}{l}\text { DesignBuilder - } \\
\text { simplificado }\end{array}$ & $\begin{array}{l}\text { EnergyPlus - } \\
\text { DesignBuilder }\end{array}$ \\
\hline \multirow{4}{*}{ PTAC } & \multirow{4}{*}{$\begin{array}{l}\text { Componente } \\
\text { equivalente }\end{array}$} & & SWERA & $-0,33 \%$ & $1,47 \%$ & $-1,77 \%$ \\
\hline & & & INMET 2016 & $-6,60 \%$ & $-9,60 \%$ & $3,32 \%$ \\
\hline & & \multirow{2}{*}{ Referência } & SWERA & $5,29 \%$ & $6,36 \%$ & $-1,01 \%$ \\
\hline & & & INMET 2016 & $-6,60 \%$ & $-11,25 \%$ & $5,24 \%$ \\
\hline \multirow{4}{*}{ PTAC } & \multirow{4}{*}{ Adiabática } & \multirow{4}{*}{ Referência } & SWERA & $-1,80 \%$ & $-1,12 \%$ & $-0,69 \%$ \\
\hline & & & INMET 2016 & $-7,90 \%$ & $-12,11 \%$ & $4,79 \%$ \\
\hline & & & SWERA & $2,97 \%$ & $6,15 \%$ & $-3,00 \%$ \\
\hline & & & INMET 2016 & $-7,19 \%$ & $-10,65 \%$ & $3,87 \%$ \\
\hline
\end{tabular}

\section{Discussão}

Em geral, a diferenças entre os resultados obtidos por simulação e pelo método simplificado se devem ao fato de o último utilizar um metamodelo baseado em RNA para cálculo da carga térmica anual de resfriamento da edificação. Esse metamodelo exige algumas simplificações para o seu uso, tal como o preenchimento direto dos valores de transmitância, absortância e capacidade térmica da cobertura, não permitindo a análise por simulação do efeito que a laje técnica (de acordo com o projeto) gera, quando avaliada como zona térmica.

A diferença entre os resultados (em módulo) obtidos pelo EnergyPlus e pelo DesignBuilder (média de $2,39 \%$, variando entre $0,01 \%$ e 7,22\%) se deve, dentre outros fatores, às distinções na modelagem da edificação, para posterior simulação. Quando utilizado o EnergyPlus, cada zona térmica da edificação foi modelada no ScketchUp e no OpenStudio, até todo o pavilhão militar ter sido representado. Quando utilizado o DesignBuilder, toda a envoltória da edificação foi modelada primeiramente, separando as zonas térmicas a posteriori. Essas distinções geraram diferenças em volumes internos de cada zona térmica, o que provocou variações no cálculo de carga térmica anual de resfriamento e no cálculo do consumo anual do sistema de condicionamento de ar. Além disso, diferenças podem ser atribuídas às diferenças do EnergyPlus: o DesignBuilder (6.1.0.006) utiliza a versão 8.9.0.001, enquanto o EnergyPlus utilizado foi o 9.1.0.001.

O software DesignBuilder já possui na sua biblioteca o arquivo climático "SWERA" para Campo Grande, MS. O mesmo não ocorre com o arquivo "INMET 2016", o qual teve que ser baixado (LABEEE/UFSC, 2019) e importado para a biblioteca. Nessa importação, alguns erros ocorreram, tais como falha na importação de valores de temperatura, de velocidade e de direção do vento, de meses iniciais e finais e de dias típicos de inverno e verão, de temperaturas de solo. O DesignBuilder permitiu a edição de alguns desses valores, o que foi realizado de acordo com o arquivo de extensão "ddy" do "INMET 2016". Porém, nem todos os dados climáticos utilizados na simulação pelo DesignBuilder puderam ser editados (o software impede que o usuário o faça). Nesse aspecto, quando não se utiliza o arquivo climático disponível na biblioteca original do DesignBuilder, o EnergyPlus apresenta vantagens, pois é uma ferramenta que permite

196 Pimentel, B. P.; Silva, A. S.; Barbosa, A. T. R.; Reis, M. de M. 
visualização e edição da infinidade de parâmetros utilizados, independentemente de qual arquivo climático seja utilizado.

Por outro lado, a utilização do DesignBuilder se mostrou vantajosa por permitir o desenho da edificação no próprio software e por atribuir adjacências entre superfícies de zonas vizinhas automaticamente. Para utilização do EnergyPlus, foi necessária a modelagem no software ScketchUp com o plugin OpenStudio, com adjacências entre as superfícies atribuídas manualmente pelo usuário, o que aumentou o tempo aplicado no processo de avaliação da edificação.

No caso da modelagem do sistema de iluminação e dos equipamentos instalados, utilizou-se o valor absoluto da potência instalada em cada zona, anulando as diferenças entre o EnergyPlus e o DesignBuilder no aspecto da área útil (ligeiramente distinta). Porém, houve diferenças de consumo energético simulado desses dois sistemas em relação aos obtidos pelo método simplificado, devido à divisão de zonas térmicas ser diferente no método simplificado e pelo fato de se preencherem valores de densidade de potência de equipamento e de iluminação (W/m ), e não valores absolutos $(\mathrm{W})$, no metamodelo.

No quesito condicionamento de ar, por exemplo, foi utilizado por Versage (2015) um sistema ideal ("IdealLoads") para treinamento do metamodelo e era de se esperar que a simulação com esse objeto forneceria as menores diferenças entre os resultados obtidos pelo método simplificado e pelo método de simulação. Porém, ao serem realizadas simulações com o objeto "PTAC", com todos os outros parâmetros mantidos, foram obtidas diferenças menores entre o método simplificado e o método de simulação. Com o "PTAC", a diferença média entre os métodos foi de 3,65\%, enquanto com "IdealLoads" foi de 4,25\%.

Além disso, tanto o metamodelo como o método de simulação da INI-C permitem a escolha da modelagem de cobertura, podendo ser adiabática ou material equivalente (mesmas propriedades térmicas da cobertura de projeto), ou a combinação de material equivalente no método simplificado com modelagem da cobertura conforme projeto no método de simulação. Com esse artigo, mostrou-se que a cobertura adiabática apresentou resultados de consumo energético menores que a cobertura modelada como componente equivalente (nesse caso, em média, 3,06\%). No caso específico da edificação estudada, a cobertura equivalente apresentou consumo energético simulado, em média, $1,61 \%$ maior que a cobertura modelada como no projeto (que nesse caso é uma zona térmica). Porém, esse resultado é mais representativo para a edificação avaliada, sem possibilitar inferências para trabalhos futuros.

\section{Conclusões}

O projeto do pavilhão tomado para estudo nesse artigo obteve ENCE Geral nível "A" quando avaliado pelo método prescritivo do RTQ-C. Uma vez que a INI-C deve substituir o regulamento anterior, uma nova avaliação foi realizada.

Foram aplicados os métodos simplificado e de simulação da INI-C ao projeto dessa edificação, obtendo-se resultados de consumo energético, carga térmica anual e ENCE Geral. Para fins de aprofundamento e detalhamento, foram avaliados 52 cenários de modelagem.

Concluiu-se que o método simplificado e o método de simulação da INI-C fornecem resultados compatíveis, podendo ambos ser aplicados sem diferenças significativas. O cenário que gerou menor diferença (em média 1,37\%) entre os métodos (simplificado e de simulação da INI-C) foi a com objeto "PTAC" de condicionamento de ar, com arquivo climático "SWERA", e com cobertura modelada como no projeto (com laje técnica funcionando como zona térmica). A maior diferença entre os métodos foi, em média, $9,82 \%$, na modelagem com objeto "PTAC", arquivo "INMET 2016", e cobertura de projeto. Apesar da diferença entre os cenários, o nível de eficiência energética não foi modificado com as diferentes formas de modelagem, obtendo-se sempre nível "A" para e edificação, com média de 58,08\% de economia do edifício na condição real em relação à de referência (equivalente à classe " $D$ ").

Apesar da INI-C recomendar a utilização do arquivo climático "INMET 2016", não há evidências sobre qual arquivo foi utilizado para o treinamento do metamodelo utilizado no método simplificado para outras cidades além de Florianópolis, SC (para qual foi utilizado o TRY). Com "SWERA", foram obtidos valores de carga térmica de resfriamento e de consumo energético anual, em média, 46,55\% e 12,64\% maiores, respectivamente, que com "INMET 2016" (análise energética mais conservadora). Além disso, as diferenças médias de carga térmica e de consumo anual entre os métodos de simulação e simplificado foram, respectivamente, de $+3,33 \%$ e $+1,51 \%$, quando utilizado "SWERA" e de $-29,44 \%$ e $-9,98 \%$, quando utilizado "INMET 2016". Assim, com utilização do "SWERA", aproximam-se os resultados entre os 
métodos de simulação e simplificado da INI-C, validando os resultados entre si. Por esses motivos, recomenda-se a utilização do "SWERA" para estudos futuros em Campo Grande, MS, que utilizem a INI-C.

Para aplicação do método de simulação, a utilização dos softwares EnergyPlus e DesignBuilder se mostrou viável, sem diferença significativa de resultados qualquer que seja utilizado (diferença máxima de 7,22\% entre os consumos obtidos pelo EnergyPlus e pelo DesignBuilder).

\section{Referências}

BAVARESCO, M. V. et al. Análise da precisão de um metamodelo para a avaliação de eficiência energética em edificações. In: ENCONTRO NACIONAL DE CONFORTO NO AMBIENTE CONSTRUÍDO, 14., Balneário Camboriu, 2017. Anais [...] Balneário Camboriu: ENCAC, 2017.

CENTRO BRASILEIRO DE EFICIÊNCIA ENERGÉTICA DE EDIFICAÇÕES. Metamodelo online baseado em RNA para cálculo da carga térmica anual de uma edificação. 2019b. Disponível em: http://pbeedifica.com.br/redes/comercial/index_with_angular.html\#. Acesso em: 17 ago. 2019.

CENTRO BRASILEIRO DE EFICIÊNCIA ENERGÉTICA DE EDIFICAÇÕES. Novo método de avaliação energética de edificações baseado em energia primária. 2019a. Disponível em: http://cb3e.ufsc.br/etiquetagem/desenvolvimento/atividades-2012-2016/trabalho-1/pesquisas. Acesso em: 30 out. 2019.

CENTRO BRASILEIRO DE EFICIÊNCIA ENERGÉTICA DE EDIFICAÇÕES. Proposta de método para avaliação de eficiência energética de edificações comerciais, de serviços e públicas: apresentação. 2017. Disponível em: http://cb3e.ufsc.br/sites/default/files/Método comercial-CT Inmetro.pdf. Acesso em: 5 out. 2019.

CLIMATE-DATA.ORG. Clima Campo Grande, MS. 2020. Disponível em: https://pt.climatedata.org/america-do-sul/brasil/mato-grosso-do-sul/campo-grande-3912/. Acesso em: 15 jan. 2020.

COMISSÃO DE OBRAS DO TERCEIRO GRUPAMENTO DE ENGENHARIA. Planta de Lay-Out (Planta Humanizada), Estudo de Insolação e Perspectivas - Construção da Companhia de Comando e Apoio (CCAp). Campo Grande: Exército Brasileiro - Diretoria de Obras Militares, 2017.

DEPARTMENT OF ENERGY. EnergyPlus 9.2.0 documentation input output reference. Washington, 2019.

EVANS, M.; SHUI, B. Country report on building energy codes in Japan. Richland: U.S. Department of Energy, 2009.

FONTANA, F.; FONSECA, R. W.; PEREIRA, F. O. R. Impacto do contexto urbano na disponibilidade de luz natural no ambiente interno e no consumo energético de iluminação artificial. In: ENCONTRO NACIONAL DE CONFORTO NO AMBIENTE CONSTRUÍDO, 15., João Pessoa, 2019. Anais [...] João Pessoa: ENCAC, 2019.

FOSSATI, M. et al. Building energy efficiency: an overview of the Brazilian residential labeling scheme. Renewable and Sustainable Energy Reviews, v. 65, p. 1216-1231, 2016.

INSTITUTO NACIONAL DE METROLOGIA, QUALIDADE E TECNOLOGIA. Anexo da Portaria INMETRO n 50/2013. Anexo Geral V - Catálogo de propriedades térmicas de paredes, coberturas e vidros. Rio de Janeiro, 2016a.

INSTITUTO NACIONAL DE METROLOGIA, QUALIDADE E TECNOLOGIA. Manual para Aplicação do RTQ-C. Rio de Janeiro, 2016b.

INSTITUTO NACIONAL DE METROLOGIA, QUALIDADE E TECNOLOGIA. Portaria $\mathbf{n}^{\circ} \mathbf{1 7}$, de $\mathbf{1 6}$ de janeiro de 2012, que aprova a retificação do RTQ-C: Regulamento Técnico da Qualidade para o Nível de Eficiência Energética de Edificações Comerciais, de Serviços e Públicas. São Paulo, 2012.

INSTITUTO NACIONAL DE METROLOGIA, QUALIDADE E TECNOLOGIA. Portaria no 248, de 10 de julho de 2018. Consulta Pública da INI-C: Instrução Normativa INMETRO para a Classe de Eficiência Energética de Edifícios Comerciais, de Serviços e Públicos. Aperfeiçoamento do RTQ-C: Regulamento Técnico da Qualidade para a Classe de Eficiência Energética de Edifícios Comerciais, de Serviços e Públicos. São Paulo, 2018. 
INTERNATIONAL ENERGY AGENCY. Energy efficiency 2018: analysis and outlooks to 2040. Paris, 2018a.

INTERNATIONAL ENERGY AGENCY. Global Energy \& CO2 Status Report. Paris, 2018 b.

INTERNATIONAL ENERGY AGENCY. Global status report for buildings and construction 2019. Paris, 2019a.

INTERNATIONAL ENERGY AGENCY. Word Energy balances: overview. Paris, $2019 \mathrm{~b}$.

LABORATÓRIO DE EFICIÊNCIA ENERGÉTICA DE EDIFICAÇÕES. Arquivos climáticos INMET 2016. 2019. Disponível em: http://www.labeee.ufsc.br/downloads/arquivos-climaticos/inmet2016. Acesso em: 2 out. 2019.

MELO, A. P. et al. Assessing the accuracy of a simplified building energy simulation model using BESTEST: The case study of Brazilian regulation. Energy and Buildings, v. 45, p. 219-228, 2012.

MELO, A. P. et al. Desenvolvimento de um método para aprimorar a precisão do método prescritivo da etiquetagem PROCEL/INMETRO para edifícios comerciais. In: ENCONTRO NACIONAL DE CONFORTO NO AMBIENTE CONSTRUÍDO, 12., Brasília, 2013. Anais [...] Brasília: ENCAC, 2013.

MINISTÉRIO DO PLANEJAMENTO, ORÇAMENTO E GESTÃO. Instrução Normativa no 2, de 4 de junho de 2014. Brasília, 2014.

MOTHERWAY, B. Energy efficiency is the first fuel, and demand for it needs to grow. 2019.

Disponível em: https://www.iea.org/commentaries/energy-efficiency-is-the-first-fuel-and-demand-for-itneeds-to-grow. Acesso em: 8 jan. 2020.

RACHID, M. N. Implementação da eficiência energética em uma edificação militar do exército brasileiro. Campo Grande, 2018. Dissertação (Mestrado em Eficiência Energética e Sustentabilidade) Universidade Federal do Mato Grosso do Sul, Campo Grande, 2018.

RORIZ, M. Classificação de Climas do Brasil - Versão 3.0. Carlos: ANTAC, 2014.

VERSAGE, R. de S. Metamodelo para estimar a carga térmica de edificações condicionadas artificialmente. Florianópolis, 2015. Tese (Doutorado em Engenharia Civil) - Universidade Federal de Santa Catarina, Florianópolis, 2015.

VIEIRA, J. C. et al. Estudo de classificação da eficiência energética do prédio 20 do CEFET-MG. In: ENCONTRO NACIONAL DE CONFORTO NO AMBIENTE CONSTRUÍDO, 15., João Pessoa, 2019. Anais [...] João Pessoa: ENCAC, 2019.

YAMAKAWA, M. A.; WESTPHAL, F. S. Influência do percentual de abertura nas fachadas e do fator solar dos vidros na etiquetagem do Procel /Inmetro : método prescritivo x simulação. In: ENCONTRO

NACIONAL DE CONFORTO NO AMBIENTE CONSTRUÍDO, 11., Búzios, 2011. Anais [...] Búzios: ENCAC, 2011.

\section{Agradecimentos}

O presente trabalho foi realizado com apoio da Universidade Federal do Mato Grosso do Sul - UFMS MEC - Brasil, da Coordenação de Aperfeiçoamento de Pessoal de Nível Superior Brasil (Capes) e do Exército Brasileiro. 


\section{Breno Pontes Pimentel}

Faculdades de Engenharia, Arquitetura, Urbanismo e Geografia | Universidade Federal do Mato Grosso do Sul | Av. Costa e Silva, Pioneiros, Cidade Universitária | Campo Grande - MS - Brasil | CEP 79070-900 | Tel.: (67) 3345-7475 | E-mail:

brenopontespimentel@gmail.com

\section{Andréa Teresa Riccio Barbosa}

Faculdades de Engenharia, Arquitetura, Urbanismo e Geografia | Universidade Federal do Mato Grosso do Sul | E-mail: andrea.barbosa@ufms.br

\section{Arthur Santos Silva}

Faculdades de Engenharia, Arquitetura, Urbanismo e Geografia | Universidade Federal do Mato Grosso do Sul | E-mail: arthur.silva@ufms.br

\section{Marcelo de Miranda Reis}

Seção de Ensino - 2 | Instituto Militar de Engenharia | Praça General Tibúrcio, 80 | Rio de Janeiro - RJ - Brasil | CEP 22290-270 | Tel.: (21) 2546-7024 | E-mail: marceloreis@ime.eb.br

\section{Ambiente Construído}

Revista da Associação Nacional de Tecnologia do Ambiente Construído Av. Osvaldo Aranha, $99-3^{\circ}$ andar, Centro

Porto Alegre - RS - Brasil

$$
\text { CEP 90035-190 }
$$

Telefone: +55 (51) 3308-4084

www.seer.ufrgs.br/ambienteconstruido www.scielo.br/ac

E-mail: ambienteconstruido@ufrgs.br 